\title{
Large-scale investigation into iceberg-tsunamis generated by various iceberg calving mechanisms
}

Valentin Heller ${ }^{1, *}$, Tommaso Attili ${ }^{1,2}$, Fan $\mathrm{Chen}^{1}$, Roman Gabl ${ }^{3,4}$ and Guido Wolters ${ }^{5}$

${ }^{1}$ Environmental Fluid Mechanics and Geoprocesses Research Group, Faculty of Engineering, University of Nottingham, Nottingham, NG7 2RD, UK,

${ }^{2}$ Department of Energy, System, Land and Construction Engineering, University of Pisa, Via Gabba 22, I-56100 Pisa, Italy,

${ }^{3}$ School of Engineering, Institute for Energy Systems, University of Edinburgh, Edinburgh, EH9 3DW, UK,

${ }^{4}$ Unit of Hydraulic Engineering, University of Innsbruck, Technikerstrasse 13, 6020

Innsbruck, Austria,

${ }^{5}$ Deltares, Coastal Structures and Waves, Boussinesqweg 1, 2629 HV Delft, The Netherlands.

*Corresponding author: Tel.: +44 1157486049.

E-mail addresses: $\quad$ valentin.heller@nottingham.ac.uk $\quad$ (V. Heller),

tommaso.attili@nottingham.ac.uk (T. Attili), fan.chen@nottingham.ac.uk (F. Chen), roman.gabl@ed.ac.uk (R. Gabl) and guido.wolters@ deltares.nl (G. Wolters). 


\section{Abstract}

Mass balance analysis of ice sheets is a key component to understand the effects of global warming with iceberg calving as a significant contributor. Calving recently generated tsunamis of up to $50 \mathrm{~m}$ in amplitude endangering human beings and coastal infrastructure. Such icebergtsunamis (IBTs) have been investigated based on 66 unique large-scale experiments conducted in a $50 \mathrm{~m} \times 50 \mathrm{~m}$ large basin at constant water depth $h$. The experiments involved five iceberg calving mechanisms: A: capsizing, B: gravity-dominated fall, C: buoyancy-dominated fall, D: gravity-dominated overturning and E: buoyancy-dominated overturning. The kinematics of the up to $187 \mathrm{~kg}$ heavy plastic blocks mimicking icebergs was measured with a motion sensor and the wave profiles were recorded with wave probes at up to 35 locations. The IBTs from the gravity-dominated mechanisms (B and D) are roughly an order of magnitude larger than from mechanisms A, C and E. Empirical equations for preliminary hazard assessment and mitigation for the maximum wave height, amplitude and period for both the near- and far-field are derived for the five calving mechanisms individually and combined. The relative released energy, Froude number and relative iceberg width are the most influential dimensionless parameters in these equations. A maximum wave height decay trend close to $(r / h)^{-1.0}$ is observed, with $r$ as the radial distance, in agreement with the theoretical wave decay from a point source. The empirical equations are applied to a past event resulting in a good agreement and the upscaled wave periods to typical Greenlandic conditions overlap with the lower spectrum of landslidetsunamis. However, empirical equations for landslide-tsunamis were found to be of limited use to predict IBTs in the far-field supporting the need of the newly introduced empirical equations for IBT hazard assessment and mitigation.

Keywords: Greenland; Iceberg calving; Iceberg-tsunami; Impulse wave; Landslide-tsunami; Outlet glacier; Physical modelling. 


\section{Introduction}

\subsection{Background}

The global mean sea level rises currently $\approx 2.7 \mathrm{~mm} /$ year including $\approx 1.5 \mathrm{~mm} /$ year due to land ice melt and retreat (Hanna et al., 2013; Box and Colgan, 2017). Mass balance analysis of ice sheets is thus a key component to understand the effects of global warming. A significant contributor to ice sheet and shelf mass balance, next to surface mass loss (surface melting, runoff) and other smaller contributors, is iceberg calving. Iceberg calving accounts for most of the mass loss from the Antarctic Ice Sheet (Benn et al., 2007) and for 32\% of the Greenland Ice Sheet (Enderlin et al., 2014) between 2009 and 2012 of its overall ice mass loss of approximately $-269 \pm 51 \mathrm{Gt} /$ year (McMillan et al., 2016).

Iceberg-calving is the sudden detachment of an iceberg from a glacier front due to a fracture. Such fractures are caused by large stresses due to gradients in the glacier velocity, imbalanced forces at the ice cliff, melting at or below the water surface and/or torques induced by buoyancy forces (Benn et al., 2007).

Icebergs calve through different mechanisms (Massel and Przyborska, 2013; Minowa et al., 2018; Heller et al., 2019c (H19 hereafter)), depending on the formation and propagation of the fractures, the geometry of the glacier terminus and its position relative to the water surface (Benn et al., 2007). Subaerial icebergs fall or overturn into the water body due to the gravity force as shown in Fig. 1 for events at the Perito Moreno Glacier, Argentina. Such events, specified as toggle, drop and serac by Minowa et al. (2018), accounted for $98 \%$ of the 420 capsizing cases observed by these authors over 39 days in 2013/14 and 2016 for the Perito Moreno Glacier. For icebergs detaching underwater, the buoyancy force is dominant and the iceberg moves vertical or overturns towards the water surface (Benn et al., 2007). Combinations of these mechanisms, e.g. of fall with overturning, are also observed and the icebergs can further be partially submerged. Once the iceberg detached from the glacier front it may capsize in 
proximity of the glacier front or in the open water (MacAyeal et al., 2011; Burton et al., 2012). In order to capture this wide range of iceberg calving mechanisms in idealised form, H19 investigated the following five mechanisms in the laboratory: A: capsizing, B: gravitydominated fall, C: buoyancy-dominated fall, D: gravity-dominated overturning and E: buoyancy-dominated overturning (Fig. 2).

Iceberg-calving generates waves, called iceberg-tsunamis (IBTs) hereafter (short for iceberg-generated tsunamis), which are the focus of this work. They are typically observed during the summer season at outlet glaciers in Greenland and the Antarctica as well as at mountain glaciers, when iceberg calving is particularly common due to high air temperatures.

Several IBTs have been observed in the recent past which destroyed harbours, fishing boats and tourist vessels in Greenland (Mendsonboaz, 2009; MacAyeal et al., 2011). Other examples include an iceberg-calving event at Tasman Glacier in New Zealand in 2011 where an iceberg overturned into the Tasman Lake resulting in a tsunami of $3.1 \mathrm{~m}$ amplitude $\approx 3.5 \mathrm{~km}$ from the glacier front (Dykes et al., 2016). 16 calving events were recorded at Helheim Glacier in Greenland in 2013/14 with the largest wave height reaching $24 \mathrm{~cm}$ at $\approx 30 \mathrm{~km}$ from the glacier front (Vaňková and Holland, 2016). Further, a calving iceberg at the Eqip Sermia Glacier generated in 2014 an IBT of 45 - $50 \mathrm{~m}$ in amplitude (Lüthi and Vieli, 2016). A last example is an iceberg reaching about $100 \mathrm{~m}$ above water which moved in proximity of the shore of the village Innaarsuit in Greenland in summer 2018 resulting in the evacuation of some of the 170 inhabitants due to IBTs threat (The Guardian, 2018).

\subsection{Previous work}

Preliminary studies into IBTs focused on aspects such as the glacier terminus stability and calving rates in the context of mass balance analysis and investigated IBTs as a side phenomenon. A pioneering study is MacAyeal et al. (2009) who measured the indirect effects 
of "micro"-tsunamis on the Ross Sea Ice Shelf with seismometers and estimated that approximately 200 events occur in this region per year. Amundson et al. (2010) measured $1 \mathrm{~m}$ high waves of $30-60 \mathrm{~s}$ periods $3 \mathrm{~km}$ from the Jakobshavn Isbræ Glacier terminus. Unfortunately, their pressure sensor started to move for waves in excess of $1 \mathrm{~m}$ preventing the specification of a reliable upper boundary for the wave height. However, they provided an estimate of $10 \mathrm{~m}$ based on visual observation at the glacier front. Minowa et al. (2018) recorded 420 calving events at the Perito Moreno Glacier in periods between 2013 and 2016 and measured IBTs $500 \mathrm{~m}$ from the glacier front with a pressure sensor. The wave amplitudes were up to $1.0 \mathrm{~m}$, the periods $5-20 \mathrm{~s}$ and the wave frequencies and amplitudes were different for subaerial and subaqueous mechanisms. Minowa et al. (2019) applied a similar method at the Bowdoin Glacier in northwest Greenland. They used time-lapse imagery to quantify the iceberg volumes of 27 main calving events in July 2015 and 2016 and measured the corresponding tsunami heights with a pressure sensor located in proximity of the glacier front at the shore. They found a positive correlation between the maximum wave amplitude and iceberg volume, which further improved when the cliff height and the distance of the measurement sensor from the glacier front were considered.

While such field observations provide reliable measurements of the IBT periods and give some indications of the wave height, which may have been strongly affected by the local bathymetry, however, modelling appears to be more appropriate to predict future events. MacAyeal et al. (2011) derived a theoretical expression for the released energy $E$ by a capsizing iceberg. $E$ is the difference between the work required to move the iceberg block in the initial $\left(W_{i}\right)$ and final $\left(W_{f}\right)$ positions to a common reference level above the water surface by considering gravity force and hydrostatic pressure force as

$$
E=W_{i}-W_{f}=\frac{1}{2} b \rho_{s} g s l^{2}(1-s / l)\left(1-\frac{\rho_{s}}{\rho_{w}}\right)
$$


$b, l$ and $s$ are the block width, height and thickness (Fig. 3), $g$ is the gravitational acceleration and $\rho_{s}$ and $\rho_{w}$ are the ice (subscript s, adopted from subaerial landslide-tsunami (SLT) research) and water (subscript w) densities, respectively. Eq. (1) for $E$ was later complemented with expressions for all five iceberg-calving mechanisms A to E by H19. MacAyeal et al. (2011) showed further that only $\approx 7 \%$ of $E$ of the capsizing iceberg is transferred into the tsunami train, which was close to 2.8 to $5.0 \%$ measured at relative radial distance $r / h=2$ for naturally capsizing icebergs by H19, with $r$ as the radial distance and $h$ as the water depth. H19 showed that the range of the transferred energy increases to 0.6 to $56.9 \%$ of $E$, if all mechanisms are considered. A further important result of MacAyeal et al. (2011) is

$$
H_{M} \approx 0.01 l,
$$

derived by relating the maximum (subscript $\mathrm{M}$ ) tsunami height $H_{M}$, found with dimensional analysis, to $E$.

Massel and Przyborska (2013) provide the theoretical water surface elevation $\eta$ in function of time $t$ and $r$ for four calving mechanisms by considering (a) the pressure impulse induced by the block on the water surface and (b) the vertical oscillation of the block in the water body:

(i) A cylindrical iceberg oriented horizontally of small height $l$, compared to the glacier front, falls frictionless on a still water surface and $\eta$ is due to (a) only.

(ii) A cylindrical iceberg of $l$ identical to the glacier front height touching the water surface is sliding into the water body with zero initial velocity and $\eta$ is due to (b) only.

(iii) A cylindrical iceberg with $l$ larger than in (i), but still smaller than the glacier front height, is falling frictionless on a water surface with $\eta$ considering both (a) and (b).

(iv) A cylindrical iceberg of identical height as the glacier front height, with thickness much smaller than the height and width, overturns relative to its base and impacts horizontally on to the water surface. Only (a) is considered with (b) neglected. 
Massel and Przyborska (2013) showed with some typical scenarios that case (ii) produces with $3-6 \mathrm{~cm}$ the smallest and case (iv) with $3.5-8.2 \mathrm{~m}$ the largest wave amplitudes.

Burton et al. (2012) conducted small-scale laboratory experiments in a $244 \mathrm{~cm} \times 30 \mathrm{~cm} \times 30$ $\mathrm{cm}$ flume (2D wave propagation) to investigate iceberg capsizing. The iceberg was modelled with $10.3 \mathrm{~cm} \times 26.7 \mathrm{~cm} \times 2.5-10.2 \mathrm{~cm}$ polyethylene plastic blocks of density $\rho_{s}=920 \mathrm{~kg} / \mathrm{m}^{3}$. They found that only $\approx 1 \%$ of the released iceberg energy is transferred into waves based on measurements $25 \mathrm{~cm}$ away from the iceberg, with most energy dissipated trough viscous drag and turbulence. Further, the wave parameters at the same location were in good agreement with Eq. (2).

H19 investigated all five iceberg calving mechanisms A to E in large-scale 3D experiments. They cross-compared the IBTs of the five mechanisms in the near-field and found that the maximum wave heights generated by mechanisms B and D are roughly an order of magnitude larger than from mechanisms A, C and E. They further showed that empirical equations for SLTs establish estimates of an upper envelope of the maximum IBT heights, however, these equations fail to predict the behaviour of the capsizing A and buoyancy-dominated mechanisms $\mathrm{C}$ and E. H19 did not provide predictive empirical equations for the maximum wave parameters nor did they look into the IBTs in the far-field.

\subsection{Aims and structure}

This study aims to introduce a new method to support IBT hazard assessment and mitigation based on empirical equations for both the near- and far-field. The tsunamigenic potential of the five iceberg-calving mechanisms A to $\mathrm{E}$ will be cross-compared in the far-field, significantly expanding the comparison of H19 who focused on the near-field only. All findings will then be related to available SLT knowledge and validated with a past IBT event in nature. 
The laboratory experiments including a dimensional analysis are discussed in Section 2. The results presented in Section 3 include new empirical equations for the maximum wave parameters in the near- and far-field as well as the wave celerity. Section 4 includes a discussion where IBTs are compared with SLTs and the new empirical equations are applied to a real event in nature. The most relevant conclusions are summarised in Section 5. The appendices include information on how the iceberg velocities for all calving mechanisms are derived (Appendix A), correlations for additional wave parameters to Section 3 (Appendix B) and details about the SLT studies included in Section 4 (Appendix C).

\section{Laboratory experiments}

\subsection{Overview}

The experimental investigation was carried out by H19 such that only the main features of this investigation are recalled. The experiments have been conducted in the $50 \mathrm{~m} \times 50 \mathrm{~m}$ Delta Basin at Deltares, Delft, as shown in Fig. 4. The effective basin size, excluding wave makers and absorbing beaches, was $40.3 \mathrm{~m} \times 33.9 \mathrm{~m}$ (Fig. 3). The experimental programme is shown in Table 1 and included 66 experiments consisting of 55 individual tests and 11 repetitions. The capsizing mechanism involved 16 experiments, the fall mechanism 30 (21 gravity- and 9 buoyancy-dominated) and the overturning mechanism 20 (14 gravity- and 6 buoyancydominated) experiments.

The icebergs were modelled with two polypropylene homopolymer blocks with a density similar to that of ice $\left(\approx 920 \mathrm{~kg} / \mathrm{m}^{3}\right)$. The blocks were released offshore (capsizing, Fig. 2) and at the vertical boundary of the basin (fall and overturning, Figs. 1 and 2). The sizes of the blocks were $0.800 \mathrm{~m} \times 0.500 \mathrm{~m} \times 0.500 \mathrm{~m}$ (block type 1 , Fig. $4 \mathrm{~b}$ ) and $0.800 \mathrm{~m} \times 0.500 \mathrm{~m} \times 0.250 \mathrm{~m}$ (block type 2, Fig. 4a). They weighted 91.2 to 93.6 and 184.6 to $187.1 \mathrm{~kg}$, respectively, 
depending on the attachments to the blocks (rod, clamp screws, plate for electromagnet, bearing).

\subsection{Calving mechanisms}

The procedures for the five calving mechanisms (Fig. 2) were as follows (Heller, 2019a; Heller et al. 2019b):

Capsizing (mechanism A in Figs. 2, 3a and 4a): The blocks in the capsizing case were held in position with a wooden rod guided through the centre of the blocks. This rod was held in position on both sides with steel profiles and was able to heave and pitch, but not to sway and surge (Fig. 4a). Capsizing was initiated in most cases by removing a fitting which stabilised the blocks. Block type 1 was stable without fitting in the initial position such that it was slightly pushed by hand, with a force in the order of $1 \mathrm{~N}$ (e.g. mimicking an external force such as wave action), to capsize. In two tests the blocks were pushed harder as discussed in Section 3.2.

Fall (mechanisms B and C in Fig. 2): The blocks were held in position with an electromagnet prior to release, which was connected to a rope as shown in Fig. 4b. The supporting frame for this electromagnet and the blocks was fixed to a steel plate at the basin wall. The blocks were moved in vertical direction with a winch system fixed to a support structure outside the wave basin (Fig. 4b). For the buoyancy-dominated fall case, the blocks were pulled under water with a rope attached to the centre of the block bottoms. For some buoyancy-dominated tests the blocks had to be stabilised in addition with a steel beam from above and both the steel beam and the rope were then released simultaneously.

Overturning (mechanisms D and E in Fig. 2): The blocks rotated around a fixed steel rod of $30 \mathrm{~mm}$ diameter. This rod was fed through two ball bearings fixed to the block surfaces. This ensured that the blocks underwent a pure rotation and were not heaving. The rod was held in position with steel profiles (Fig. 4b) and was located either below (mechanism D) or above 
(mechanism E) the blocks. For some buoyancy-dominated tests the blocks had to be stabilised in addition with a steel beam from above and the blocks started to move once the steel beam was removed.

\subsection{Dimensional analysis}

The nine governing parameters shown in Table 2 and Fig. 5 were considered for the correlations of the IBT features such as the maximum wave heights and their decay with $r$ and the wave propagation angle $\gamma$. These nine parameters are the released energy $E$, water depth $h$, iceberg velocity $V_{s}$, iceberg thickness $s$, iceberg width $b$, iceberg volume $\forall_{s}$, iceberg density $\rho_{s}$, water density $\rho_{w}$ and gravitational acceleration $g . b$ was varied by changing the orientation of the two block types 1 and 2 in the initial position (Tables 1 and 2). The velocity $V_{s}$ corresponds to the fastest moving section of the block and was derived based on the motion sensor data (Chen et al., 2020). The density $\rho_{s}$ changed slightly due to attachments to the block (Tables 1 and 2). $E$ (Section 1.2) is an instrumental parameter to collapse very large and very small wave data given that $E$ varies over a large range. All theoretical expressions and figures for $E$, next to Eq. (1), are available in the Supplementary Material of H19.

The nine governing parameters involve the three units length [L], mass $[\mathrm{M}]$ and time $[\mathrm{T}]$ such that they can be expressed in dimensionless form based on three reference quantities (Buckingham, 1914). The reference quantities $g, h$ and $\rho_{w}$ have been selected resulting in the six dimensionless parameters the relative released energy $E_{r}=E /\left(h^{4} g \rho_{w}\right)$, Froude number $\mathrm{F}=$ $V_{s} /(g h)^{1 / 2}$, relative iceberg thickness $S=s / h$, relative iceberg width $B=b / h$, relative iceberg volume $V=\forall_{s} / h^{3}$ and the relative density $D=\rho_{s} / \rho_{w}$ (Table 2$)$.

Scale effects due to the kinematic viscosity $v_{w}$ and surface tension $\sigma_{w}$ were neglected for the analysed wave parameters in this Froude scaling experiments given that the Weber number W $=\rho_{w} g h^{2} / \sigma_{w} \geq 75,552$ and Reynolds number $\mathrm{R}=g^{1 / 2} h^{3 / 2} / v_{w} \geq 2,033,835$ were large and satisfied 
the limitations $W \geq 5,000$ and $R \geq 300,000$ established for the physically closely related phenomenon of SLTs (Heller et al., 2008).

\subsection{Measurement system}

The block kinematics was recorded at full sampling rate of $\approx 74 \mathrm{~Hz}$ with a 9 Degree of Freedom motion sensor (Adafruit BNO055). This rate slightly varied within an experiment as this was the largest possible rate the Arduino was able to cope with. The sensor was located in a watertight enclosure and attached to the block surface (inset Fig. 4b). The absolute measurement uncertainty for $V_{s}$ is between \pm 0.03 and $\pm 0.08 \mathrm{~m} / \mathrm{s}$, depending on the calving mechanism (H19). Two cameras (a 5 MP PointGrey ZBR2-PGEHD-50S5C-CS, which recorded at $15 \mathrm{~Hz}$, and a $2 \mathrm{MP}$ IOIndustries Flare 2M280-CXP, which recorded at $100 \mathrm{~Hz}$ ) were used for general observations. The wave features were recorded with up to 35 resistance type wave probes on one side of the block axis, given that the wave field was symmetric. They recorded at $100 \mathrm{~Hz}$ with an estimated accuracy of $\pm 0.1 \mathrm{~mm}$. Initially, they were calibrated daily by changing the water level in the basin but less frequently later as the calibration parameters did not change significantly over time (with an estimated maximum change $<2 \%$ ) for given wave probe locations.

The origins of the cylindrical coordinate systems $(r, z, \gamma)$ are shown in Fig. 3. They are located for all calving mechanisms in vertical direction $z$ on the water surface. In the horizontal plane the origin is located at the block centre for the capsizing case (Fig. 3a) and at the front of the steel plate in the centre of the block in cross-shore direction for all other calving mechanisms (Fig. 3c). The angle $\gamma$ is defined positive in clockwise direction. The wave probes are numbered anti-clockwise starting at $\gamma=0^{\circ}$ and from small to large $r$ (Fig. 3a,c). Table 3 shows the locations of all wave probes. 
The time in all experiments was adjusted such that $t=0 \mathrm{~s}$ corresponds to the time when the blocks started to move for experiments where they were initially in contact with the surrounding water, or when the blocks reached the water surface when they were initially fully subaerial. The raw data of the motion sensor were processed in Matlab ${ }^{\circledR}$ to transform the accelerations in global coordinates and to derive the block velocities and positions as described by Chen et al. (2020). The water surface time series were individually shortened to remove data affected by reflection from the basin boundaries (Attili, 2019). The wave probe data were then filtered with a low-pass filter with a cut off frequency at 9 to $11 \mathrm{~Hz}$. For wave probes A9, A17 and A25 in the capsizing experiments and B21/C21, B24/C24 and B32/C32 for all fall and overturning experiments a low-pass filter with a cut off frequency at 3.0 or $3.5 \mathrm{~Hz}$ was applied to remove large high-frequency noise. For 3 out of all 2278 time series the signal-to-noise ratio after filtering remained large such that these 3 series were excluded from further analysis.

\section{Experimental results}

\subsection{Selected typical experiments}

Fig. 6 shows image series of five selected typical experiments. This involves a mechanism A (Fig. 6a), B (Fig. 6b), C (Fig. 6c), D (Fig. 6d) and E (Fig. 6e). The time intervals between the pictures are $2.67 \mathrm{~s}$ in Fig. 6a,e and $1.33 \mathrm{~s}$ in Fig. 6b,c,d. The free water surface elevation $\eta$ versus time $t$ corresponding to the experiments in Fig. 6 are shown in Fig. 7. These wave profiles were all measured at relative radial distance $r / h=2$ (Fig. 3 and Table 3 ). The scales on the $y$ axes in Fig. 7 vary by up to a factor of 20 . The wave magnitudes significantly differ for the mechanisms A to E; mechanism D results in the largest tsunami heights followed by mechanism B. The three remaining mechanisms resulted in up to a factor of 26 smaller waves. Further, the wave trains consist of several nonlinear waves for all mechanisms, similar as for SLTs (Heller and Spinneken, 2015). The largest wave amplitude is observed in the middle of the wave train 
for the slower moving mechanisms A and C. For the gravity-dominated mechanisms B and D the largest wave is observed earlier in the wave train.

\subsection{IBT characteristics}

Fig. 8 shows the overall trend of the relative maximum wave heights $H_{M} / h$ versus the relative distance $r / h$ (Fig. 8a,c,e,g,i) and $\gamma$ (Fig. 8b,d,f,h,j) for all 66 experiments and calving mechanisms. The wave heights within a given calving mechanism scatter by up to an order of magnitude and mechanisms B and D generate much larger waves than mechanisms $\mathrm{A}, \mathrm{C}$ and E. $H_{M}$ of mechanism A reach 0.6 to $1.1 \%$ of the initial vertical dimension of the mass for naturally capsizing icebergs in agreement with Eq. (2). The most distinct trend observed for all mechanisms is the wave height decay with $r / h$. Further, the wave heights tend to be the largest at $\gamma=0^{\circ}$, the main impulse direction of the blocks (Fig. 3), and decrease with increasing $\gamma$. This trend is more distinct in Fig. 8f,h,j than for mechanism B in Fig. 8d. For mechanism A (Fig. 8b) the waves decrease from $\gamma=0$ to $-90^{\circ}$ before increasing again from -90 to $-180^{\circ}$. $H_{M} / h$ increases again for some of the mechanisms at $\gamma=-75^{\circ}$, which is due to the influence of the basin wall at $\gamma=-90^{\circ}$ where the waves may be affected by the presence of the boundary (Di Risio et al., 2009; Heller and Spinneken, 2015).

The maximum values of the wave height $H_{M}$, amplitude $a_{M}$ and period $T_{M}$ over all experiments for each iceberg-calving mechanism are shown in Table $4 . H_{M}$ and $a_{M}$ were analysed individually as the linear wave criterion $2 a_{M}=H_{M}$ does generally not apply to IBTs. Further, this is also common for SLT research given that SLT run-up and dam overtopping equations, which may also be applied to IBTs, rely on $H, a$ and/or $T$ (Heller et al., 2009). $H$ and $a$ tend to decrease and $T$ tends to increase with $r$. In order to present a coherent set of wave parameters, $T_{M}$ is defined at the identical position within the wave train and at the identical wave probe as $H_{M}$ was measured, even though $T$ may be significantly larger for larger $r$. Further, 
all $T$ herein are based on an up-crossing analysis. Table 4 shows that $H_{M}$ and $T_{M}$ reached up to $0.119 \mathrm{~m}(16 \%$ of $h)$ and $2.24 \mathrm{~s}$, respectively. $H_{M}$ and $a_{M}$ of the gravity dominated mechanisms B and D are significantly larger than of the remaining mechanisms, e.g. for $H_{M}$ the difference between $H_{M}$ in mechanisms $\mathrm{B}$ and $\mathrm{D}$ and $\mathrm{A}, \mathrm{C}$ and $\mathrm{E}$ is a factor of $0.119 / 0.016=7.4$ to $0.119 / 0.008=14.9($ Table 4$)$.

Fig. 9 shows the relative maximum wave heights $H_{M} / h$ for all 66 experiments versus a combination of the six dimensionless parameters from Section 2.3. Shown are correlations for each individual mechanism (Fig. 9a-e) and for all mechanisms combined (Fig. 9f). The optimised correlations were found with a regression analysis based on the least-square approach algorithm trust-region-reflective. Power laws were selected as they are simple, robust and often applied in SLT research. Some restrictions were imposed on the exponents to obtain physically meaningful results (Attili, 2019). This involves positive exponents for $E_{r}, \mathrm{~F}, S, B$ and $V$ to consider that more energetic, faster and larger icebergs result in larger IBTs than less energetic, slower and smaller icebergs. A larger relative density $D$ is also expected to result in larger IBTs for the gravity-dominated mechanisms (positive exponent for $D$ ) with this effect reversing (negative exponent for $D$ ) for buoyancy-dominated cases as a lighter mass will reach the water surface faster creating larger waves. The empirical equations and coefficients of determination $R^{2}$ resulting from Fig. 9 are

Capsizing:

$$
\frac{H_{M}}{h}=1.39\left(E_{r}^{0.26} \mathrm{~F}^{1.73} S^{0.20} B^{0.20} V^{0.48} D^{-1.74}\right)^{0.92} \quad\left(R^{2}=0.49\right)
$$

Gravity-dominated fall:

$$
\frac{H_{M}}{h}=0.25\left(E_{r}^{0.20} \mathrm{~F}^{1.31} S^{0.60} B^{1.62} V^{0.20} D^{0.15}\right)^{0.50} \quad\left(R^{2}=0.95\right)
$$

Buoyancy-dominated fall:

$$
\frac{H_{M}}{h}=1.41\left(E_{r}^{0.20} \mathrm{~F}^{1.36} S^{0.10} B^{0.30} V^{0.48} D^{-1.42}\right)^{0.98} \quad\left(R^{2}=0.64\right)
$$


Gravity-dominated overturning:

$$
\frac{H_{M}}{h}=0.27\left(E_{r}^{0.20} \mathrm{~F}^{0.92} S^{0.47} B^{0.91} V^{0.23} D^{0.22}\right)^{0.50} \quad\left(R^{2}=0.92\right)
$$

Buoyancy-dominated overturning:

$$
\frac{H_{M}}{h}=0.13\left(E_{r}^{0.23} \mathrm{~F}^{1.65} S^{1.27} B^{0.40} V^{0.20} D^{-0.98}\right)^{0.50} \quad\left(R^{2}=0.95\right)
$$

All mechanisms combined:

$$
\frac{H_{M}}{h}=0.26\left(E_{r}^{0.20} \mathrm{~F}^{1.72} S^{0.53} B^{1.10} V^{0.20} D^{0.10}\right)^{0.50} \quad\left(R^{2}=0.92\right)
$$

The most important parameter in Eqs. (3) to (8) is F with an exponent in the range of $0.92 \cdot 0.50=0.46$ to $1.73 \cdot 0.92=1.59$. Further important are the relative slide width $B$, with an exponent of up to $1.62 \cdot 0.50=0.81$, as well as $E_{r}$. $E_{r}$ is influential due to its exponent in the range of 0.10 to 0.24 combined with a large range of $E_{r}$ over nearly three orders of magnitude (Table 2). Generally speaking, the influences of $S, V$ and $D$ on $H_{M} / h$ are small. The relative iceberg velocity and released energy tend therefore to be more relevant for the heights of IBTs than the relative iceberg volume and dimensions. The pre-sign of the exponent of $D$ is positive for the gravity-dominated mechanisms and negative for the remaining three mechanisms. However, the overall influence of $D$ on $H_{M} / h$ is still small given that it varies only in the range 0.91 to 0.94 (Table 2), and this small variation is associated with a larger uncertainty in the exponent of $D$ compared to the remaining exponents. Nevertheless, $D$ is a relevant parameter in the empirical correlations as it is physically relevant for IBTs (Eq. (1)), it is the only parameter with an exponent changing its pre-sign and it simplifies comparisons with SLTs (e.g. with Eq. (C.1)). The two encircled data points in Fig. 9a are from the harder pushed capsizing block experiments. The data typically scatter $\pm 30 \%$ relative to the predictions with a particularly tight fit achieved for mechanism E in Fig. 9e. Fig. 9 confirms that the tsunami heights generated by the gravity-dominated mechanisms B and D are roughly an order of magnitude larger than for the remaining mechanisms over all conducted experiments. The correlation in Fig. 9f based 
on Eq. (8) simplifies the prediction with one equation describing all mechanisms. Most data lie within the $\pm 40 \%$ bounds, however, the insert reveals that Eq. (8) tends to over-predict mechanisms A, C and E and therefore operates on the safe side.

The decays of the normalised relative maximum wave heights $H_{M} / h$ with $r / h$ for all 66 experiments in the far-field for each individual mechanism and all mechanisms combined are shown in Fig. 10. The corresponding empirical equations were again found with the least-square approach. For the wave decay, in addition to the restrictions imposed in the least-square approach for $H_{M}$ in Fig. 9, a negative exponent for $r / h$ was imposed to consider the decay of $H_{M} / h(r / h, \gamma)$ with $r / h$ (Fig. 8) due to spatial wave energy spread. The cosine function for $\gamma$ was selected to consider the larger wave height on the iceberg axis $(\gamma=0$, Fig. 8$)$, in analogy to SLTs studies (Huber and Hager, 1997; Heller and Spinneken, 2015), whilst the exponent of the cosine (1.00 and 0.50$)$ and the factor 0.50 for $\gamma$ resulted from the data correlation. This resulted in the empirical equations

Capsizing:

$$
\frac{H_{M}}{h}\left(\frac{r}{h}, \gamma\right)=0.40\left(E_{r}^{0.64} \mathrm{~F}^{1.40} S^{0.80} B^{0.56} V^{0.10} D^{-1.96}\right)^{0.50}\left(\frac{r}{h}\right)^{-0.99} \cos ^{0.50}\left(\frac{\gamma}{2}\right)\left(R^{2}=0.40\right)(9)
$$

Gravity-dominated fall:

$$
\frac{H_{M}}{h}\left(\frac{r}{h}, \gamma\right)=0.46\left(E_{r}^{0.20} \mathrm{~F}^{1.22} S^{0.67} B^{1.52} V^{0.25} D^{1.02}\right)^{0.50}\left(\frac{r}{h}\right)^{-0.91} \cos \left(\frac{\gamma}{2}\right)\left(R^{2}=0.93\right)
$$

Buoyancy-dominated fall:

$$
\frac{H_{M}}{h}\left(\frac{r}{h}, \gamma\right)=0.26\left(E_{r}^{0.23} \mathrm{~F}^{1.40} S^{0.80} B^{1.12} V^{0.10} D^{-1.42}\right)^{0.50}\left(\frac{r}{h}\right)^{-0.98} \cos ^{0.50}\left(\frac{\gamma}{2}\right)\left(R^{2}=0.84\right)(1
$$

Gravity-dominated overturning:

$$
\frac{H_{M}}{h}\left(\frac{r}{h}, \gamma\right)=0.35\left(E_{r}^{0.20} \mathrm{~F}^{1.38} S^{0.20} B^{0.47} V^{0.30} D^{0.17}\right)^{0.50}\left(\frac{r}{h}\right)^{-0.95} \cos \left(\frac{\gamma}{2}\right)\left(R^{2}=0.86\right)
$$

Buoyancy-dominated overturning:

$$
\frac{H_{M}}{h}\left(\frac{r}{h}, \gamma\right)=0.10\left(E_{r}^{0.28} \mathrm{~F}^{1.06} S^{0.93} B^{0.31} V^{0.28} D^{-1.05}\right)^{0.50}\left(\frac{r}{h}\right)^{-0.92} \cos ^{0.50}\left(\frac{\gamma}{2}\right)\left(R^{2}=0.89\right)(13
$$


All mechanisms combined:

$$
\frac{H_{M}}{h}\left(\frac{r}{h}, \gamma\right)=0.27\left(E_{r}^{0.28} \mathrm{~F}^{1.08} S^{0.14} B^{0.71} V^{0.20} D^{0.20}\right)^{0.50}\left(\frac{r}{h}\right)^{-0.90} \cos ^{0.50}\left(\frac{\gamma}{2}\right)\left(R^{2}=0.80\right)(14)
$$

The parameters $\mathrm{F}, B$ and $E_{r}$ are also important in Eqs. (9) to (14) and $S, V$ and $D$ play a less significant role. The data in Fig. 10 follow the predictions based on Eqs. (9) to (14) reasonably well and most data lie within the $\pm 50 \%$ bounds. Particularly striking for all mechanisms is the approximate wave decay $\sim(r / h)^{-1.0}$, corresponding both to the theoretically expected decay for a wave from a point source propagating on an open water surface (Kranzer and Keller, 1959) and the decay found by Heller and Spinneken (2015) for SLTs in a basin. Such an experimental confirmation is not straight forward for a number of reasons: the momentum in many IBT experiments is partially directed in the wave propagation direction, most IBTs in the experiments propagated on semi-, rather than full-circles and IBTs are dispersive. These are reasons why a number of 3D SLT studies predicted a wave decay with an exponent for $r / h$ significantly smaller than -1.0 (e.g. Eqs. (C.1) and (C.2)). The encircled outliers in Fig. 10a are again from the harder pushed capsizing block experiments. A reasonably good fit for the data of all calving mechanisms combined is achieved in Fig. 10f considering the variety of underlying physical principles involved in the five calving mechanisms. The corresponding Eq. (14) results in a coefficient of determination of $R^{2}=0.80$. However, the data scatter is particularly large in proximity of the iceberg calving location at $r / h=2$ where water splashes reached the wave probes in some of the experiments (Heller et al., 2019a).

Appendix B includes empirical equations for the relative maximum wave amplitude $a_{M} / h$ (Fig. B.1), its decay with $r / h$ (Fig. B.2) and the relative maximum wave period $T_{M}(g / h)^{1 / 2}$ and its decay with $r / h$ (Fig. B.3). Also included are the first (leading) wave heights, amplitudes and periods and their decays with $r / h$ for all mechanisms combined (Figs. B.4 and B.5).

Over all mechanisms and both the near- and far-field, the waves at which $H_{M}$ were measured are in the ranges $0.0002 \leq H_{M} / h \leq 0.158,0.16 \leq L / h \leq 17.46$ and $0.00017 \leq \mathrm{U}=H L^{2} / h^{3} \leq 6.24$, 
with $L$ as the wavelength. Waves classify as deep- $(L / h<2)$, intermediate- $(2 \leq L / h \leq 20)$ or shallow-water waves $(L / h>20)$. The Ursell parameter $U$ specifies the wave non-linearity with $U \rightarrow 0$ indicating linear waves and waves with $U<10$ may be described with Stokes-wave theory (Sorensen, 1993). Further, $U \approx 1$ indicates solitary waves, which were not observed in this study. The waves investigated herein at which $H_{M}$ were measured can therefore be classified as linear- to Stokes-like waves propagating as deep- to intermediate-water waves. This applies similarly to the first waves, except of three values expanding into the shallowwater regime (Section 3.3, Fig. 11a).

\subsection{Wave celerity}

The wave celerity $c$ is important to indicate the available time to react to an IBT at a specific distance from the calving location. It further helps to estimate the wavelength $L$, for example by using the regular wave expression $L=T c$. Fig. 11a shows the relative first (subscript 1) wave celerity $c_{1} /[g L /(2 \pi) \tanh (2 \pi h / L)]^{1 / 2}$ over $L / h$ with $L$ derived with the linear wave dispersion relation (Dean and Dalrymple, 2004) and Fig. 11b shows $c_{1} /(g h)^{1 / 2}$ as a function of the relative mean (subscript m) wave amplitude $a_{m} / h$ of two subsequent wave probes. $c$ was derived with the distance between two subsequent wave probes divided by the travel time of the wave crest. About $9.5 \%$ of the $\approx 1900$ potential data points for $c$ could not be derived because they were part of the three removed times series or the signal was cut to avoid contaminated waves due to wave reflection (Section 2.4). However, it is unlikely that this missing data would change the overall trends in Fig. 11. The symbols in Fig. 11 indicate the calving mechanism showing no particular trend in relation to $c$. The data are compared with the general linear (Eq. (15)) and shallow-water (Eq. (16)) wave celerity, respectively, as

$$
\begin{aligned}
& c=\left[\frac{g L}{2 \pi} \tanh \left(\frac{2 \pi h}{L}\right)\right]^{1 / 2} \\
& c=(g h)^{1 / 2}
\end{aligned}
$$


The data scatter for all mechanisms relative to $c_{1} /[g L /(2 \pi) \tanh (2 \pi h / L)]^{1 / 2}=1$ (Fig. 11a) and $c_{1} /(g h)^{1 / 2}=1$ (Fig. 11b), mainly due to dispersion and the difference between the phase and group velocity. The overall average in Fig. 11a is 1.03 and in Fig. $11 \mathrm{~b}$ it is 0.89 , i.e. most of the data points lie above 1 in Fig. 11a and below 1 in Fig. 11b. Eq. (16) results in a less exact approximation for $c_{1}$ than Eq. (15), given that most first IBTs are in the deep- to intermediatewater range (Fig. 11a) (Section 3.2). However, Eq. (16) may be preferred as it requires no prior knowledge of $L$, in contrast to Eq. (15).

\section{Discussion of results}

\subsection{Introduction}

Predictions based on some of the new IBT Eqs. (3) to (14) are compared with predictions from empirical equations from the significantly further developed research field of SLTs in this Section 4. Further, the IBT features are upscaled to typical nature conditions, the empirical equations are used to replicate a past case and some limitations of the empirical equations are discussed. Attili (2019) shows that the discrepancy between theoretically predicted IBTs based on Massel and Przyborska (2013) and the measured IBTs is generally large, up to a factor of 10 for $a_{M}$ for case (ii) and $\approx 40 \%$ for $a_{M}$ for case (iv) (Section 1.2), such that this comparison is not included herein.

\subsection{Comparison with SLTs}

The 45 - 50 m large IBT observed at Eqip Sermia (mechanism B) was successfully replicated by Lüthi and Vieli (2016) with the SLT hazard assessment method of Heller et al. (2009). This section aims to clarify as far mechanisms different from B, based on different physical principles (e.g. buoyancy-dominated mechanisms, overturning), can be predicted with available 
empirical equations for SLTs. This potentially enables to transfer knowledge of the established research field of SLTs to the relatively new field of IBTs.

This section focuses on the iceberg- and landslide-tsunami comparison in the far-field, which has not been addressed by H19. The wave heights in the far-field in a flume (2D) can be an order of magnitude larger than in 3D (Heller and Spinneken, 2015; Ruffini et al., 2019). Further, the IBTs investigated herein are in the Stokes-like wave regime (Grummel, 2018; Heller and Hager, 2011) being relevant as different wave types decay differently. The following comparison focuses therefore on SLT studies involving Stokes-like waves in 3D. Studies meeting these criteria are Huber and Hager (1997), Panizzo et al. (2005), Heller et al. (2009), Mohammed and Fritz (2012), Heller and Spinneken (2015) and Evers et al. (2019a). These studies are summarised in Appendix $\mathrm{C}$ along with the dimensionless parameters in Table C.1.

Fig. 12a shows the wave height $H / h\left(r / h, \gamma=0^{\circ}\right)$ versus $r / h$ in double-logarithmic form for the ranges included in Table C.1. In order to compare these studies, they were arranged relative to the reference point ( $(\circ)$ at $H / h\left(r / h=7.5, \gamma=0^{\circ}\right)=0.05$, a location covered by all studies. The wave height decay of the present study is in good agreement with Heller and Spinneken (2015) and the scenario ex $=-0.76$ and ex2 $=-3.48$ of Mohammed and Fritz (2012) (Appendix C). The maximum deviation of these two studies relative to the present study is only $15 \%$ in the investigated $r / h$ ranges. The deviation from Huber and Hager (1997) is nearly 50\% at $r / h=30$ and an even larger deviation is observed for Evers et al. (2019a) (for an impulse product parameter $\mathrm{P}=0.24, B=1.07$ and an impact angle $\alpha=90^{\circ}$, Appendix C). The agreement between the results of the present study and the scenario ex1 $=-1.36$ and $e x 2=-2.07$ of Mohammed and Fritz (2012) and Evers et al. (2019a) with $\mathrm{P}=0.02, B=0.05$ and $\alpha=90^{\circ}$ (Appendix C) becomes worse, with a difference at $H / h\left(r / h=35, \gamma=0^{\circ}\right)$ of up to a factor of 3 . Potential reasons for this mismatch are the rather small dimensionless parameters investigated in the present study compared to SLT studies (Table C.1). Further, Evers et al. (2019a) analysed 
the wave decay exclusively in the far-field, while the wave decay of the present study starts in the near- and expands into the far-field $(r / h \geq 2.0)$. The smallest wave height decay is predicted by Panizzo et al. (2005) with only $H / h \sim(r / h)^{-0.44}$.

A similar picture as for $H / h\left(r / h, \gamma=0^{\circ}\right)$ emerges for $a / h\left(r / h, \gamma=0^{\circ}\right)$; the decays found in some of the SLT studies match well with IBTs (the empirical equations of Panizzo et al., 2005, and of Heller and Spinneken, 2015, perform best), but others match not well at all. This is in more detail discussed in Attili (2019).

Fig. 12b shows the decay of $H / h(r / h=7.5, \gamma)$ with $\gamma$, based on the same studies as in Fig. 12a, and again with reference point (o) at $H / h\left(r / h=7.5, \gamma=0^{\circ}\right)=0.05$. Generally speaking, the decay of IBTs with $\gamma$ is poorly predicted with SLT equations, with the best agreement achieved by the study of Evers et al. (2019a) (the data points of both scenarios overlap, Appendix C). Evers et al. (2019a) found that the wave decay is a function of the slide impact angle $\alpha$, which is $\alpha=90^{\circ}$ for IBTs in contrast to most SLT studies involving lower values for $\alpha$ (Table C.1). Thus, the IBT heights are more uniform with $\gamma$, expressed as $\cos ^{0.50}(\gamma / 2)$ and $\cos (\gamma / 2)$ in Eqs. (9) to (14), than for SLTs. Given that the empirical SLT equations matching the IBT height $H / h(r / h, \gamma=0)$ and those matching the $H / h(r / h=7.5, \gamma)$ decay best are not the same, it is not surprising that the decay for $r / h$ and $\gamma$ combined for IBTs is unsatisfactory predicted by SLT equations. The corresponding figures are discussed by Attili (2019).

H19 found that the maximum IBT heights $H_{M}$ of the most violent gravity-dominated mechanisms B and D are reasonable well predicted by SLT equations in the near-field, but less violent cases within mechanisms $\mathrm{B}$ and $\mathrm{D}$ and the entire range of mechanisms $\mathrm{A}, \mathrm{C}$ and $\mathrm{D}$ are not well predicted. The additional analysis in this section into the far-field reveals that IBTs of all mechanisms are unsatisfactory predicted with empirical equations for SLTs. There are, however, still many physical processes related between IBTs and SLTs (frequency dispersion, wave period range, wave types, effect of reservoir geometry, effect of mass type, etc.) making 
a literature review into SLTs still valuable for IBTs. Nevertheless, the newly introduced empirical equations of the present research are much better suited for hazard assessment of IBTs than existing empirical equations for SLTs.

\subsection{Application to real cases}

\subsubsection{Application in nature}

The measured IBT parameters in the experiments can directly be applied to nature events in dimensionless form or upscaled in dimensional form by applying Froude scaling laws. This is demonstrated with some of the parameters shown in Table 4 and with applying the new empirical equations to predict the IBT of the 2014 Eqip Sermia Glacier event. Given that only measurements for $a$, and not for $H$, are available for this event, the expressions in Appendix B are applied.

The scale factor $\lambda$ is the ratio between a characteristic length in nature (subscript $\mathrm{N}$ ) and the corresponding length in the model (subscript M) (Heller, 2011). Herein, the water depth $h$ is selected for this purpose. In nature, $h=125 \mathrm{~m}(\lambda=125$ based on the experiments conducted at $h=1.00 \mathrm{~m}$ ) is typical e.g. for the Bowdoin Glacier in Greenland (Minowa et al., 2019). A more extreme value $h \approx 800 \mathrm{~m}(\lambda \approx 800)$ is observed in Greenland at the Helheim Glacier (Vaňková and Holland, 2016) and the Jakobshavn Isbræ (Amundson et al., 2010). The maximum wave height measured over all experiments is $H_{M}=0.119 \mathrm{~m}$ (Table 4) with a wave period $T_{M}=2.12$ $\mathrm{s}$ for mechanism B corresponding to $H_{M, N}=\lambda H_{M, M}=125 \cdot 0.119 \mathrm{~m}=14.9 \mathrm{~m}$ and $T_{M, N}=\lambda^{1 / 2} T_{M, M}$ $=125^{1 / 2} 2.12=23.7 \mathrm{~s}$ in nature. Given the small section of the glacier front above water in relation to $h$, more realistic than mechanisms B and D based on $\lambda=800$ and the investigated parameter ranges (Table 2) is a buoyancy-dominated fall case, represented by $H_{M}=0.016 \mathrm{~m}$ and $T_{M}=1.99 \mathrm{~s}$ (Table 4). This corresponds to $H_{M, N}=\lambda H_{M, M}=800 \cdot 0.016 \mathrm{~m}=12.8 \mathrm{~m}$ and $T_{M, N}$ $=\lambda^{1 / 2} T_{M, M}=800^{1 / 2} 1.99=56.3 \mathrm{~s}$ in nature. This wave period matches well within $T=30-60 \mathrm{~s}$ 
observed by Amundson et al. (2010). $T$ tends to increase further with $r$ with the largest measured value $T=5.53 \mathrm{~s}$ (mechanism $\mathrm{B}$ at wave probe $\mathrm{C} 35$ ) over all experiments and wave probe locations scaling to $T_{N}=156.4 \mathrm{~s}$. Most IBT periods are thus much larger than for typical gravity Atlantic Ocean waves (10 s), and they indeed overlap with the lower spectrum of (landslide)tsunamis.

\subsubsection{Eqip Sermia Glacier case}

The new empirical IBT Eqs. (B.2) and (B.6) are applied to the 2014 Eqip Sermia Glacier case herein. The calving mechanism of this case was more complex than a gravity-dominated fall mechanism B as the ice mass slid on a concave-shaped glacier front surface (Fig. 3 in Lüthi and Vieli, 2016) and most likely disintegrated. Nevertheless, mechanism B represents this real case best out of the investigated ones. The governing parameters for this event are summarised in Table 5 where the water depth $h=30 \mathrm{~m}$, iceberg length $l=200 \mathrm{~m}$, iceberg thickness $s=50$ $\mathrm{m}$ and iceberg volume $\forall_{\mathrm{s}}=9 \times 10^{5} \mathrm{~m}^{3}$ are estimates of Lüthi and Vieli (2016). The iceberg width $b$ was estimated via $\forall_{\mathrm{s}}, l$ and $s$ as $b=\forall_{s} /(l s)=90 \mathrm{~m}$. The released energy $E=7.2 \times 10^{11}$ J was evaluated based on Table S1 of H19 for mechanism B and an initial position of the iceberg centroid $z_{c}=100 \mathrm{~m}$ (Fig. 3 of Lüthi and Vieli, 2016). Lüthi and Vieli (2016) found $V_{s}=39-42$ $\mathrm{m} / \mathrm{s}$ based on energy conservation taking friction losses into account. Here a reasonably close value of $V_{s}=34.8 \mathrm{~m} / \mathrm{s}$ was derived with the expression for mechanism B given in Table A.1 based on $V_{b}=40.8 \mathrm{~m} / \mathrm{s}$, a mass of $m_{s}=\forall_{s} \rho_{s}=8.1 \times 10^{8} \mathrm{~kg}$ and an added mass of $M_{s}=1.4 \times$ $10^{8} \mathrm{~kg}$ (with an added mass coefficient $C_{M}=0.78$ for $b / s=1.8$ ). The lower part of Table 5 includes the governing dimensionless parameters $E_{r}, \mathrm{~F}, V, S, B$ and $D$.

Eq. (B.2) for mechanism B results in a maximum wave amplitude $a_{M}=36 \mathrm{~m}$ and Eq. (B.6) for all mechanisms combined in $a_{M}=37 \mathrm{~m}$. This corresponds to an underestimation of the measured $a_{M}=45-50 \mathrm{~m}$ of Lüthi and Vieli (2016) by $20-28 \%$ (mechanism B) and $18-26 \%$ 
(all mechanisms). This is a satisfactory agreement considering the uncertainties in predicting the governing parameters, the violation of dimensionless parameter ranges and model effects (Section 4.3.3).

\subsubsection{Limitations}

A requirement for applying the new empirical Eqs. (3) to (14) and Eqs. (B.1) to (B.20) is that the dimensionless parameters in nature are within the investigated ranges (Table 2). In nature, $E_{r}, \mathrm{~F}, S, B$ and $V$ start from 0 such that the upper limits are most relevant. These combined limits for the 2014 Eqip Sermia (Lüthi and Vieli, 2016) and the 2011 Tasman Glacier cases (Dykes et al., 2016) as well as the recorded cases by Minowa et al. (2018) and Minowa et al. (2019) for the Perito Moreno and Bowdoin Glaciers are $E_{r} \leq 90.0, \mathrm{~F} \leq 2.03, S \leq 1.67, B \leq$ 3.00 and $V \leq 33.3$ (all given by the extreme case Eqip Sermia). The investigated parameter ranges in this study (Table 2) are all within these limits. $D$ in nature is not expected to deviate significantly from the investigated conditions. The introduced equations are all empirical with uncertain prediction capabilities outside the parameter limitations. However, the underlying physics will not abruptly change from a certain dimensionless limit such that still good preliminary estimates may be achieved even if parameter ranges are violated. This was at least the case for the 2014 Eqip Sermia Glacier case, where, despite the violation of parameter ranges, a good agreement with observations in nature was achieved (Section 4.3.2).

Model effects can also be responsible for deviations between observations in nature and predictions based on empirical equations. These equations were derived under idealised conditions, essentially involving prismatic rigid icebergs, idealised calving mechanisms, a constant water depth and a 3D water body geometry (laterally unrestricted, freely propagating waves). Evers et al. (2019b) showed that large deviations from these idealisations alter the SLT features significantly and their quantifications of these effects may also be applied to IBTs. A 
rigid iceberg compared to a granular (fractured) iceberg is likely to overestimate the wave magnitude up to a factor of two (Heller and Spinneken, 2013; Evers et al., 2019b), the effect of a changing bathymetry on the wave height can be estimated with Green's law (Evers et al., 2019 b) and the water body geometry (e.g. 2D compared to 3D) alters the wave magnitude by an order of magnitude or more in the far-field (Heller and Spinneken, 2015; Ruffini et al., 2019; Evers et al., 2019b). More research is required to quantify the effect of none-idealised iceberg geometries and combined iceberg-calving mechanisms and the prediction of the iceberg calving itself (Bassis and Jacobs, 2013; Todd et al., 2018) is outside the scope of the present work.

If the parameter limitations are strongly violated or if the real conditions significantly deviate from the investigated idealisations, then prototype specific physical model tests (Fuchs et al., 2011) or numerical simulations (Chen et al., 2020) are recommended. These approaches result in more accurate predictions as they consider the specific iceberg and water body geometries and bathymetry.

\section{Conclusions}

The 66 unique large-scale iceberg-tsunami (IBT) experiments of Heller et al. (2019) have been exploited to derive new empirical equations for both the near- and far-field for IBT hazard assessment and mitigation. These experiments have been conducted in a $50 \mathrm{~m} \times 50 \mathrm{~m}$ basin with two prismatic polypropylene homopolymer blocks of up to $187 \mathrm{~kg}$ weight mimicking icebergs. The experiments involved the five iceberg calving mechanisms: A: capsizing, B: gravity-dominated fall, C: buoyancy-dominated fall, D: gravity-dominated overturning and E: buoyancy-dominated overturning. The released energy $E$, water depth $h$, iceberg velocity $V_{s}$, iceberg thickness $s$, iceberg width $b$ and the iceberg volume $\forall_{s}$ have been varied. The iceberg density $\rho_{s}$ was close to that of ice and the water density $\rho_{w}$ and gravitational acceleration $g$ were constant (Table 2). The slide kinematics was measured with a 9-Degree of Freedom motion 
sensor, the wave profiles with up to 35 wave probes for different wave propagation angles $\gamma$ up to a radial distance of $r=35 h$ and cameras were used for general observations. The main conclusions of this study are:

- The IBT features can be expressed as a function of six dimensionless parameters: the relative released energy $E_{r}=E /\left(h^{4} g \rho_{w}\right)$, Froude number $\mathrm{F}=V_{s} /(g h)^{1 / 2}$, relative iceberg thickness $S=s / h$, relative iceberg width $B=b / h$, relative iceberg volume $V=\forall_{s} / h^{3}$ and the relative density $D=\rho_{s} / \rho_{w}$, with the parameter ranges shown in Table 2 .

- Empirical equations for the most relevant IBT parameters in both the near- and farfield were presented for each individual iceberg calving mechanism and all mechanisms combined to support preliminary IBT hazard assessment and mitigation.

- More energetic, faster and larger icebergs generate larger IBTs as shown by the positive exponents of $E_{r}, \mathrm{~F}, S, B$ and $V$ in the empirical equations.

- $\mathrm{F}, B$ and $E_{r}$ were found to be the most dominant dimensionless parameters in the correlations with $S, V$ and $D$ playing a less significant role.

- The IBT heights generated by the gravity-dominated mechanisms B and D are roughly an order of magnitude larger than by mechanisms A, C and E. Subaerial icebergs of a given volume and geometry are therefore significantly more hazardous in terms of tsunami generation than neutrally buoyant or underwater icebergs.

- The maximum tsunami height decays approximately with $(r / h)^{-1.0}$, in agreement with theory and some subaerial landslide-tsunami (SLT) studies, while the effect of $\gamma$ can be captured with a cosine function.

- The IBTs at which the maximum wave heights $H_{M}$ were measured can be classified as linear- to Stokes-like waves propagating as deep- to intermediate-water waves. 
- The wave celerity of the first wave can roughly be predicted with the linear shallowwater wave celerity; a better prediction is possible with the general linear wave celerity (Eq. (15)), provided an estimate for the wavelength is available.

- Predictions of the IBT height and amplitude decays in the far-field with established empirical equations for SLTs are overall unsatisfactory; SLT equations are therefore only suitable to predict the most violent IBT heights of mechanisms B and D and to provide an estimate of an upper envelope of $H_{M}$ over all mechanisms in the near-field (Heller et al., 2019c), but SLT equations are less instrumental for the far-field.

- Upscaling the results to nature based on Froude scaling laws shows that the wave periods are much larger than for typical gravity Atlantic Ocean waves (10 s) and overlap with the lower spectrum of (landslide-)tsunamis.

- The new empirical equations replicate the 2014 Eqip Sermia Glacier event with an underestimation of $20-28 \%$. This deviation is acceptable considering the uncertainties in predicting the governing parameters, the violation of dimensionless parameter ranges and model effects.

Ongoing work numerically models some of the IBT laboratory experiments with a computational fluid dynamics solver. This solver can also be applied to real events including complex iceberg geometries, water body geometries and bathymetries and combined iceberg calving mechanisms (Chen et al., 2019; 2020). 


\section{Notation}

a = wave amplitude, $\mathrm{m}$;

$a_{0, c 1} \quad=$ initial wave crest, $\mathrm{m}$;

$a_{0, t 1} \quad=$ initial wave trough, $\mathrm{m}$;

A = iceberg lateral submerged surface, $\mathrm{m}^{2}$;

$A_{H} \quad=$ iceberg surface perpendicular to the direction of motion, $\mathrm{m}^{2}$;

$b \quad=$ iceberg width, $\mathrm{m}$;

$B \quad$ = relative iceberg width;

$c \quad=$ wave celerity, $\mathrm{m} / \mathrm{s}$;

$C_{a} \quad=$ inertia coefficient;

$C_{d} \quad=$ drag coefficient;

$C_{d, f r i c}=$ friction coefficient between the iceberg and water;

$C_{M} \quad=$ added mass coefficient;

$D \quad$ = relative density;

$e_{0} \quad=$ initial submergence of the bottom of the iceberg, $\mathrm{m}$;

ex $1, e x 2=$ exponents;

$E \quad=$ released energy, $\mathrm{kgm}^{2} / \mathrm{s}^{2} ;$

$E_{k} \quad=$ kinetic energy, $\mathrm{kgm}^{2} / \mathrm{s}^{2} ;$

$E_{r} \quad=$ relative released energy;

$f \quad=$ friction coefficient;

$\mathrm{F} \quad=$ Froude number;

$F_{b} \quad=$ buoyancy force, $\mathrm{kgm} / \mathrm{s}^{2} ;$

$F_{g} \quad=$ gravity force, $\mathrm{kgm} / \mathrm{s}^{2}$;

$g \quad=$ gravitational acceleration, $\mathrm{m} / \mathrm{s}^{2}$;

$h \quad=$ still water depth, m; 


$$
\begin{aligned}
& H \quad \text { = wave height, } \mathrm{m} \text {; } \\
& l \quad=\text { iceberg length, } \mathrm{m} ; \\
& L \quad=\text { wavelength, } \mathrm{m} \text {; } \\
& m_{s} \quad=\text { iceberg mass, } \mathrm{kg} \text {; } \\
& M \quad \text { = relative slide mass; } \\
& M_{s} \quad=\text { added mass, } \mathrm{kg} \text {; } \\
& \mathrm{P} \quad=\text { impulse product parameter; } \\
& r \quad=\text { radial distance, } \mathrm{m} \text {; } \\
& r_{0} \quad=\text { impact radius, } \mathrm{m} \text {; } \\
& r^{*} \quad=\text { surrogate radial wave propagation distance, } \mathrm{m} \text {; } \\
& R \quad \text { = running resistance force, } \mathrm{kgm} / \mathrm{s}^{2} \text {; } \\
& \mathrm{R}=\text { = Reynolds number; } \\
& R^{*} \quad=\text { relative surrogate radial wave propagation distance; } \\
& R^{2} \quad=\text { coefficient of determination; } \\
& s \quad=\text { iceberg thickness, } \mathrm{m} \text {; } \\
& S \quad=\text { relative iceberg thickness; } \\
& t \quad=\text { time, } \mathrm{s} \\
& t_{s}=\text { characteristic time of submerged landslide motion, } \mathrm{s} ; \\
& T \quad \text { = wave period, } \mathrm{s} \text {; } \\
& \text { U = Ursell parameter; } \\
& V \quad=\text { relative iceberg volume; } \\
& V_{b} \quad=\text { block velocity immediately before impact, } \mathrm{m} / \mathrm{s} \text {; } \\
& V_{s} \quad=\text { iceberg velocity, } \mathrm{m} / \mathrm{s} ; \\
& \forall_{g} \quad=\text { slide grain volume, } \mathrm{m}^{3} \\
& \forall_{s} \quad=\text { iceberg volume, } \mathrm{m}^{3} \text {; }
\end{aligned}
$$




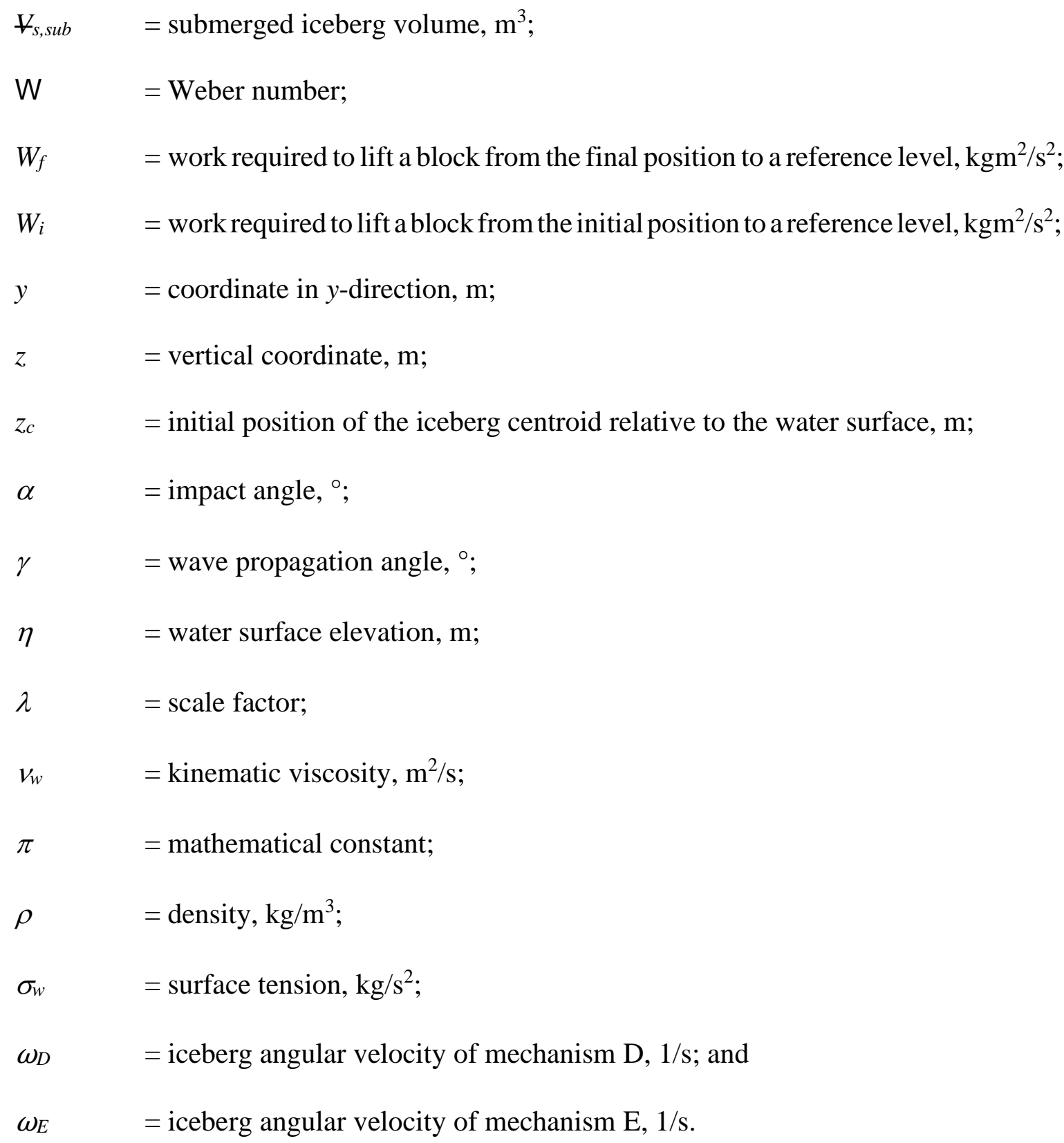

\section{Subscript}

$\mathrm{m} \quad=$ mean;

meas $=$ measured;

$\mathrm{M} \quad=$ maximum, model;

$\mathrm{N} \quad=$ nature;

pred $\quad=$ predicted;

$\mathrm{s} \quad=$ slide, used for ice herein (adopted from SLT research); 


$$
\begin{array}{ll}
\mathrm{w} & =\text { water; } \\
1 & =\text { first, section } 1 ; \text { and } \\
2 & =\text { section } 2 .
\end{array}
$$
Abbreviation
H19= Heller et al. $(2019 \mathrm{c})$;
IBT = iceberg-tsunami;
SLT = subaerial landslide-tsunami;
2D $\quad=$ two-dimensional (flume) , and
3D $=$ three-dimensional (basin).

\section{Acknowledgment}

Dr Markus Brühl and Dr Xuexue Chen are acknowledged for having supported the experiments and funding application and Dr Helge Fuchs and Dr Savvas Triantafyllou for comments on the funding application. Thanks go to Miss Elsa Büchner, Mr Daniel Fox, Miss Lina Grummel and Mr Sheng Yang for their contributions within BEng and MSc projects. Prof Stefano Pagliara is acknowledged for supporting the exchange of the $2^{\text {nd }}$ author to the University of Nottingham within his MSc project. The personnel at Deltares is acknowledged for the excellent support prior and during the test campaign. This project has received funding from the European Union's Horizon 2020 research and innovation programme under grant agreement No 654110, HYDRALAB+. The raw data of the presented data are available on the HYDRALAB+ website (Heller, 2019b), some further data $\left(V_{s}, E\right.$, etc.) in the Supplementary Material of H19 and two experiments will be released as a validation test on the SPHERIC website (Chen and Heller, 2020). 


\section{Appendix A. Iceberg velocity}

The iceberg velocity $V_{s}$, corresponding to the fastest moving section of the block, needs to be estimated before the empirical equations in Section 3 and Appendix B can be applied. Expressions for $V_{s}$ are summarised in Table A.1 along with basic assumptions. Full details on how these expressions were derived are given by Attili (2019). The expressions are based on Burton et al. (2012), Massel and Przyborska (2013) and Attili (2019).

For mechanism A, the expression for $V_{s}$ is based on the assumption that the released energy $E$ of the iceberg equals to its kinetic energy $E_{k}$ (Burton et al., 2012). For mechanism B and the mass starting above the water surface $\left(z_{c}>l / 2\right)$, the impact force transmitted by the iceberg on the water body is assumed to be equal to the change of momentum of the iceberg (Massel and Przyborska, 2013) resulting in the velocity immediately after impact, taken as $V_{s}$. This requires the block velocity $V_{b}$ immediately before impact, derived with potential and kinetic energy conservation including friction, and relying on the added mass $M_{s}$ (Patton, 1964). For mechanism B and the mass being initially in contact with the water, Newtons $2^{\text {nd }}$ law is applied including gravity force, buoyancy force and running resistance composed of the friction across the lateral submerged surface and the inertia force (Table A.1).

For mechanism C, Newton's $2^{\text {nd }}$ law is applied if $z_{c}<-l / 2$. The considered forces are gravity, buoyancy and running resistance forces, with the latter only considering the drag force with a drag coefficient $C_{d}=1.05$ for a cube. The same principle and forces are applied if the block in mechanism $\mathrm{C}$ is partially submerged with the running resistance then composed of the friction across the lateral submerged surface and the inertia force.

Mechanism D relies on the same equation as mechanism B, including $M_{s}$ (Patton, 1964), but now with $V_{b}=\omega_{D} l$. The iceberg angular velocity $\omega_{D}$ was expressed empirically based on $V_{s}$ measured in the laboratory experiments and the dimensionless parameters (Section 2.3) as

$$
\frac{\omega_{D} l}{\sqrt{g h}}=2.29\left(E_{r}^{0.73} S^{0.15} B^{0.33} V^{-0.85} D^{-3.99}\right) \quad \quad\left(R^{2}=0.99\right)
$$


For mechanism E, $V_{s}=\omega_{E} l$ is used with the angular velocity $\omega_{E}$ correlated with the experimental data resulting in

$$
\frac{\omega_{E} l}{\sqrt{g h}}=0.28\left(E_{r}^{0.23} S^{-0.10} B^{-0.42} V^{-0.05} D^{0.09}\right) \quad\left(R^{2}=1.00\right)
$$

Fig. A.1 shows the predicted (subscript pred) velocities $V_{s, p r e d}$ with the expressions in Table A.1 versus the measured (subscript meas) $V_{s, \text { meas }}$ in the experiments. Most points lie within the $\pm 30 \%$ boundaries showing that $V_{s}$ can well be predicted under idealised laboratory conditions. The same expressions may be applied to estimate $V_{s}$ in nature.

\section{Appendix B. Further wave parameters}

This Appendix B includes the correlations of further wave parameters to complement Section 3. Fig. B.1 shows the maximum relative wave amplitude $a_{M} / h$ versus a dimensionless parameter combination and Fig. B.2 shows the normalised $a_{M} / h$ decay versus $r / h$. The corresponding empirical equations are:

Capsizing:

$$
\frac{a_{M}}{h}=0.93\left(E_{r}^{0.71} \mathrm{~F}^{1.32} S^{0.31} B^{0.67} V^{0.36} D^{-2.20}\right)^{0.68} \quad\left(R^{2}=0.34\right)
$$

Gravity-dominated fall:

$$
\frac{a_{M}}{h}=0.13\left(E_{r}^{0.20} \mathrm{~F}^{1.66} S^{0.21} B^{1.46} V^{0.20} D^{0.20}\right)^{0.50} \quad\left(R^{2}=0.82\right)
$$

Buoyancy-dominated fall:

$$
\frac{a_{M}}{h}=0.38\left(E_{r}^{0.43} \mathrm{~F}^{2.10} S^{0.15} B^{1.73} V^{0.27} D^{-2.20}\right)^{0.52} \quad\left(R^{2}=0.90\right)
$$

Gravity-dominated overturning:

$$
\frac{a_{M}}{h}=0.20\left(E_{r}^{0.20} \mathrm{~F}^{1.12} S^{0.20} B^{1.20} V^{0.43} D^{0.15}\right)^{0.50} \quad\left(R^{2}=0.96\right)
$$

Buoyancy-dominated overturning:

$$
\frac{a_{M}}{h}=0.10\left(E_{r}^{0.24} \mathrm{~F}^{1.68} S^{1.27} B^{1.40} V^{0.23} D^{-0.96}\right)^{0.50} \quad\left(R^{2}=0.75\right)
$$


All mechanisms combined:

$$
\frac{a_{M}}{h}=0.14\left(E_{r}^{0.20} \mathrm{~F}^{2.07} S^{0.10} B^{1.20} V^{0.20} D^{0.40}\right)^{0.50} \quad\left(R^{2}=0.91\right)
$$

\section{Capsizing:}

$$
\frac{a_{M}}{h}\left(\frac{r}{h}, \gamma\right)=0.33\left(E_{r}^{0.79} \mathrm{~F}^{1.40} S^{0.81} B^{0.83} V^{0.10} D^{-1.08}\right)^{0.50}\left(\frac{r}{h}\right)^{-0.77} \cos ^{0.50}\left(\frac{\gamma}{2}\right)\left(R^{2}=0.39\right)
$$

Gravity-dominated fall:

$$
\frac{a_{M}}{h}\left(\frac{r}{h}, \gamma\right)=0.21\left(E_{r}^{0.20} \mathrm{~F}^{1.44} S^{0.29} B^{1.55} V^{0.25} D^{1.07}\right)^{0.50}\left(\frac{r}{h}\right)^{-0.91} \cos \left(\frac{\gamma}{2}\right)\left(R^{2}=0.89\right)
$$

Buoyancy-dominated fall:

$$
\frac{a_{M}}{h}\left(\frac{r}{h}, \gamma\right)=0.25\left(E_{r}^{0.40} \mathrm{~F}^{1.40} S^{0.80} B^{0.96} V^{0.10} D^{-1.21}\right)^{0.50}\left(\frac{r}{h}\right)^{-1.02} \cos ^{0.50}\left(\frac{\gamma}{2}\right)\left(R^{2}=0.86\right)(\mathrm{B} .9)
$$

Gravity-dominated overturning:

$$
\frac{a_{M}}{h}\left(\frac{r}{h}, \gamma\right)=0.21\left(E_{r}^{0.20} \mathrm{~F}^{1.55} S^{0.20} B^{0.43} V^{0.25} D^{0.17}\right)^{0.50}\left(\frac{r}{h}\right)^{-1.06} \cos \left(\frac{\gamma}{2}\right)\left(R^{2}=0.84\right)
$$

Buoyancy-dominated overturning:

$$
\frac{a_{M}}{h}\left(\frac{r}{h}, \gamma\right)=0.18\left(E_{r}^{0.63} \mathrm{~F}^{1.38} S^{0.86} B^{0.30} V^{0.33} D^{-0.75}\right)^{0.50}\left(\frac{r}{h}\right)^{-0.97} \cos ^{0.50}\left(\frac{\gamma}{2}\right)\left(R^{2}=0.88\right)
$$

All mechanisms combined:

$$
\frac{a_{M}}{h}\left(\frac{r}{h}, \gamma\right)=0.14\left(E_{r}^{0.20} \mathrm{~F}^{1.27} S^{0.10} B^{0.76} V^{0.20} D^{0.16}\right)^{0.50}\left(\frac{r}{h}\right)^{-0.98} \cos ^{0.50}\left(\frac{\gamma}{2}\right)\left(R^{2}=0.78\right)(\mathrm{B}
$$

Fig. B.3 shows the relative wave period $T_{M}(g / h)^{0.50}$ of $H_{M}$ for all experiments versus a dimensionless parameter combination (Fig. B.3a) as well as the normalised $T_{M}(g / h)^{0.50}$ versus $r / h$ (Fig. B.3b) for all calving mechanisms combined resulting in

$$
\begin{array}{ll}
T_{M}\left(\frac{g}{h}\right)^{0.50}=12.07\left(E_{r}^{0.16} B^{-0.24} V^{0.24} D^{3.00}\right) & \left(R^{2}=0.39\right) \\
T_{M}\left(\frac{g}{h}\right)^{0.50}\left(\frac{r}{h}, \gamma\right)=4.80\left(E_{r}^{0.05} B^{-0.06} V^{0.10} D^{2.99}\right)^{0.79}\left(\frac{r}{h}\right)^{0.34} & \left(R^{2}=0.35\right)
\end{array}
$$

F and $S$ are excluded from Eqs. (B.13) and (B.14) as they do not improve the correlations. Further, $T_{M}$ in Eq. (B.14) was assumed to be independent from $\gamma$. 
Figs. B.4 and B.5 include the correlations for the first wave parameters for all mechanisms combined including the relative wave height $H_{1} / h$ (Fig. B.4a) and amplitude $a_{1} / h$ (Fig. B.4b) versus a dimensionless parameter group, the normalised $H_{1} / h$ (Fig. B.4c) and $a_{1} / h$ (Fig. B.4d) versus $r / h$, the relative first wave period $T_{1}(g / h)^{0.50}$ versus a dimensionless parameter group (Fig. B.5a) and the normalised $T_{1}(g / h)^{0.50}$ versus $r / h$ (Fig. B.5b). The empirical equations based on Figs. B.4 and B.5 are

$$
\begin{array}{lr}
\frac{H_{1}}{h}=0.35\left(E_{r}^{0.33} \mathrm{~F}^{1.14} S^{0.35} B^{0.50} V^{0.55} D^{0.40}\right)^{0.59} & \left(R^{2}=0.89\right) \\
\frac{a_{1}}{h}=0.16\left(E_{r}^{0.28} \mathrm{~F}^{0.91} S^{0.56} B^{0.22} V^{0.77} D^{0.40}\right)^{0.63} & \left(R^{2}=0.82\right) \\
\frac{H_{1}}{h}\left(\frac{r}{h}, \gamma\right)=0.39\left(E_{r}^{0.40} \mathrm{~F}^{0.34} S^{0.19} B^{0.46} V^{0.20} D^{0.19}\right)^{0.69}\left(\frac{r}{h}\right)^{-1.20} \cos ^{0.50}\left(\frac{\gamma}{2}\right)\left(R^{2}=0.80\right) \\
\frac{a_{1}}{h}\left(\frac{r}{h}, \gamma\right)=0.17\left(E_{r}^{0.38} \mathrm{~F}^{0.51} S^{0.92} B^{0.69} V^{0.20} D^{0.20}\right)^{0.54}\left(\frac{r}{h}\right)^{-1.21} \cos ^{0.50}\left(\frac{\gamma}{2}\right)\left(R^{2}=0.68\right) \\
T_{1}\left(\frac{g}{h}\right)^{0.50}=7.22\left(E_{r}^{0.10} B^{-0.39} V^{0.10} D^{3.00}\right)^{0.42} & \left(R^{2}=0.11\right) \\
T_{1}\left(\frac{g}{h}\right)^{0.50}\left(\frac{r}{h}, \gamma\right)=9.51\left(E_{r}^{0.05} B^{-0.08} V^{0.05} D^{3.00}\right)^{0.97}\left(\frac{r}{h}\right)^{0.24} & \left(R^{2}=0.57\right)
\end{array}
$$

\section{Appendix C. Details of SLT studies}

The SLT studies and empirical equations used in Section 4.2 are summarised here with the dimensionless parameter limitations given in Table C.1. Huber and Hager (1997) conducted 150 experiments in a $6 \mathrm{~m}$ wide and $10 \mathrm{~m}$ long basin with water depths $0.12 \leq h \leq 0.36 \mathrm{~m}$. Granular slide material was released on a $0.5 \mathrm{~m}$ wide hill slope running out into the basin. In addition, they also included data from case studies of snow avalanches and glacier calving with $\rho_{s} \approx 920 \mathrm{~kg} / \mathrm{m}^{3}$. The Froude number $\mathrm{F}$ in Table C.1 is defined with the slide front velocity. Huber and Hager (1997) provided $0.09 \leq \forall_{g} /\left(b h^{2}\right) \leq 2.57$, where $\forall_{g}$ is the slide grain volume, rather than a range for the relative slide mass $M$. Based on this data, they derived the following empirical equation for the maximum relative wave height 


$$
\frac{H_{M}}{h}\left(\frac{r}{h}, \gamma\right)=1.76 \sin \alpha D^{1 / 4}\left(\frac{\forall_{g}}{b h^{2}}\right)^{0.50}\left(\frac{r}{h}\right)^{-2 / 3} \cos ^{2}\left(\frac{2 \gamma}{3}\right)
$$

Panizzo et al. (2005) conducted 288 3D block model tests. The rigid slides were released into a $12 \mathrm{~m}$ long and $6 \mathrm{~m}$ wide tank with $h=0.4$ and $0.8 \mathrm{~m}$. The slide was impacting in the corner of the basin and the basin mimicked a quarter of a water tank with the side walls as symmetry planes. A spring system at the bottom of the water tank stopped the slide abruptly once it reached the slope toe. F in Table C.1 is based on the slide front velocity and the slide front angle was $90^{\circ}$. Panizzo et al. (2005) provided $0.02 \leq \forall_{s} / h^{3} \leq 0.70$, rather than a range for $M$, as well as the dimensionless slide front surface $0.04 \leq s b / h^{2} \leq 0.68$ and the dimensionless time of characteristic submerged landslide motion $0.39 \leq t_{s}(g / h)^{1 / 2} \leq 5.11$. $t_{s}$ considers the time between slide impact and stop. Panizzo et al. (2005) describe the relative maximum wave height (with the splash zone data excluded) as

$$
\frac{H_{M}}{h}\left(\frac{r}{h}, \gamma\right)=0.07\left(\frac{\frac{t_{S}}{(h / g)^{1 / 2}}}{\frac{s b}{h^{2}}}\right)^{-0.45}(\sin \alpha)^{-0.88}\left(\frac{r}{h}\right)^{-0.44} \exp (0.6 \cos \gamma)
$$

with

$$
\frac{t_{s}}{(h / g)^{1 / 2}}=0.43\left(\frac{s b}{h^{2}}\right)^{-0.27} \mathrm{~F}^{-0.66}(\sin \alpha)^{-1.32}
$$

Heller et al. (2009) derived the following 3D equation for the maximum wave height

$$
\frac{H_{M}}{h}\left(\frac{r}{h}, \gamma\right)=(3 / 2) \mathrm{P}^{4 / 5}\left(\frac{r}{h}\right)^{-2 / 3} \cos ^{2}\left(\frac{2 \gamma}{3}\right)
$$

based on the impulse product parameter P of Heller and Hager (2010) defined as

$$
\mathrm{P}=\mathrm{F} S^{0.50} M^{0.25}\{\cos [(6 / 7) \alpha]\}^{0.50}
$$

$M=m_{s} /\left(\rho_{w} b h^{2}\right)$ is the relative mass with the slide mass $m_{s}$. Eq. (C.4) was theoretically derived based on the 2D granular slide data from Heller and Hager (2010), a 2D to 3D transformation method implicitly included in Huber and Hager (1997) and by using the 3D decay term $(r / h)^{-2 / 3} \cos ^{2}(2 \gamma / 3)$ of Eq. (C.1). Several applications of Heller et al. (2009) confirmed that Eq. (C.4) results in realistic predictions (e.g. Fuchs and Boes, 2010; Heller and Hager, 2014; 
Battaglia et al., 2015; Heller and Spinneken, 2015) such that Eq. (C.4) is nowadays perhaps the most applied SLT equation for hazard assessment. The parameter limitations are given in Table C.1 with $F$ based on the slide centroid velocity.

Mohammed and Fritz (2012) conducted 88 tests within a 3D subaerial granular slide study in a $48.8 \mathrm{~m}$ long and $26.5 \mathrm{~m}$ wide basin at water depths of $0.3 \leq h \leq 1.2 \mathrm{~m}$. F in Table C.1 is based on the slide front velocity and $\alpha=27.1^{\circ}$ was constant. They also specified the relative landslide lengths $2.5<\forall_{s} /(s b h)<6.8$ (corresponding to $l / h$ for a rectangular block) and relative volumes $0.25<\forall_{s} / h^{3}<30$ in addition to the parameters given in Table C.1. The relative first wave height is composed of the first wave crest and trough amplitudes as

$$
\frac{H_{M, 1}}{h}\left(\frac{r}{h}, \gamma\right)=0.31 \mathrm{~F}^{2.10} S^{0.6}\left(\frac{r}{h}\right)^{e x 1} \cos \gamma+0.70 \mathrm{~F}^{0.96} S^{0.43}\left[\frac{l}{h}\right]^{-0.50}\left(\frac{r}{h}\right)^{e x 2} \cos \gamma
$$

with

$$
\text { ex } 1=-1.2 \mathrm{~F}^{0.25} S^{-0.02} B^{-0.33} \text { and } e x 2=-1.6 \mathrm{~F}^{-0.41} B^{-0.02}\left[\frac{l}{h}\right]^{-0.14}
$$

Heller and Spinneken (2015) conducted 18 SLT experiments in a basin of unobstructed size of $7.4 \mathrm{~m} \times 20.0 \mathrm{~m}$ with $h=0.24$ and $0.48 \mathrm{~m}$. They avoided wave reflection in their data for the first wave in the entire range $3.0 \leq r / h \leq 35.0$ and $0^{\circ} \leq \gamma \leq 73^{\circ}$ (Table C.1) by repeating the 18 experiments twice with different shore orientations within the basin. The slide masses were modelled with three rigid slides of weight of $32.5,60.1$ and $82.7 \mathrm{~kg}$, maximum lengths of 0.35 , 0.60 and $0.88 \mathrm{~m}$, a constant thickness $s=0.12 \mathrm{~m}$ and a constant slide front angle of $45^{\circ} . \mathrm{F}$ is based on the slide centroid impact velocity. They expressed the maximum wave height as

$$
\frac{H_{M, 1}}{h}\left(\frac{r}{h}, \gamma\right)=2.75 \mathrm{~F}^{0.67} S^{1.00} M^{0.60}\left(\frac{r}{h}\right)^{-1.0} \cos ^{2\left\{1+\exp \left[-0.2\left(\frac{r}{h}\right)\right]\right\}}\left(\frac{2 \gamma}{3}\right)
$$

Evers et al. (2019a) conducted 74 SLT experiments in a $4.5 \mathrm{~m} \times 8.0 \mathrm{~m}$ basin with deformable mesh-packed slides. They used a videometric measurement system, in contrast to wave probes used in all other studies in Appendix $\mathrm{C}$, to achieve a quasi-continuous representation of the 
water surface. Evers et al. (2019a) investigated the first wave crest and through amplitudes separately in function of $P$ resulting in the maximum wave height

$$
\begin{aligned}
& \frac{H_{M, 1}}{h}\left(\frac{r}{h}, \gamma\right)=\frac{a_{0, c 1}}{h} \exp \left[-0.4\left(\frac{a_{0, c 1}}{h}\right)^{-0.3} \sqrt{R^{*}}\right]\left[\operatorname{sech}\left(\frac{3.2 \gamma}{90^{\circ}}\right)\right]^{\cos [(6 / 7) \alpha] \exp \left(-0.15 \sqrt{R^{*}}\right)}+ \\
& \frac{a_{0, t 1}}{h} \exp \left[-0.4\left(\frac{a_{0, t 1}}{h}\right)^{-0.3} \sqrt{R^{*}}\right]\left[\operatorname{sech}\left(\frac{3.6 \gamma}{90^{\circ}}\right)\right]^{\cos [(6 / 7) \alpha] \exp \left(-0.15 \sqrt{R^{*}}\right)}
\end{aligned}
$$

with the initial wave crest $a_{0, c 1}$ and wave trough $a_{0, t 1}$ given as

$$
\frac{a_{0, c 1}}{h}=0.2 \mathrm{P}^{0.50} B^{0.75}\{\cos [(6 / 7) \alpha]\}^{0.25} \text { and } \frac{a_{0, t 1}}{h}=0.35\{\mathrm{P} B \cos [(6 / 7) \alpha]\}^{0.50}
$$

$r / h$ is defined by Evers et al. (2019a) as the sum of the relative impact radius $r_{0} / h$ and the relative surrogate radial wave propagation distance $R^{*}=r^{*} / h$

$$
\frac{r}{h}=\frac{r_{0}}{h}+\frac{r^{*}}{h}
$$

with

$$
\frac{r_{0}}{h}=2.5\{\mathrm{P} B \cos [(6 / 7) \alpha]\}^{0.25}
$$

Eqs. (C.6) and (C.9) require further specifications as the governing parameters (Table 2) enter the decay exponents; the extreme values for $e x 1=-0.76$ and -1.36 (and $e x 2=-3.48$ and -2.07 , respectively) were computed based on the extremes of the investigated range for mechanism B of the present study, given the similarity of this mechanism to SLTs. The two most extreme experiments of mechanism $\mathrm{B}\left(\mathrm{P}=0.02, b=0.50 \mathrm{~m}, B=0.50\right.$ and $\alpha=90^{\circ} ; \mathrm{P}=$ $0.24, b=0.80 \mathrm{~m}, B=1.07$ and $\alpha=90^{\circ}$ ) were also used to provide an upper and lower decay range for Eq. (C.9), resulting in $a_{0, c 1} / h=0.01, a_{0, t 1} / h=0.02$ and $r_{0} / h=0.54$, and $a_{0, c 1} / h=0.07$, $a_{0, t 1} / h=0.08$ and $r_{0} / h=1.22$. These two scenarios for Eqs. (C.6) and (C.9) are included in Fig. 12. 


\section{References}

Amundson, J.M., Fahnestock, M., Truffer, M., Brown, J., Lüthi, M.P., Motyka, R.J., 2010. Ice mélange dynamics and implications for terminus stability, Jakobshavn Isbræ, Greenland. J. Geophys. Res. 115 (F01005).

Attili, T., 2019. Analysis of iceberg-tsunamis from large-scale experiments. MSc thesis. University of Pisa, Pisa.

Bassis, J.N., Jacobs, S., 2013. Diverse calving patterns linked to glacier geometry. Nature Geosci. 6, 833-836.

Battaglia, D., Strozzi, T., Bezzi, A., 2015. Landslide hazard: Risk zonation and impact wave analysis for the Bumbuma Dam-Sierra Leone. Engineering Geology for Society and Territory-Vol. 2:1129-1134, G. Lollino et al. eds., Springer, Basel.

Benn, D.I., Warren, C.R., Mottram, R.H., 2007. Calving processes and the dynamics of calving glaciers. Earth-Sci. Rev. 82 (3-4), 143-179.

Box, J.E., Colgan, W.T. 2017. Sea level rise contribution from Arctic land ice: 1850-2100. In: Snow, Water, Ice and Permafrost in the Arctic (SWIPA) 2017. 219-230. Arctic Monitoring and Assessment Programme (AMAP), Oslo, Norway.

Buckingham, E., 1914. On physically similar system-Illustrations of the use of dimensional equations. Phys. Rev. 4, 345-376.

Burton, J.C., Amundson, J.M., Abbot, D.S., Boghosian, A., Cathles, L.M., Correa-Legisos, S., Darnell, K.N., Guttenberg, N., Holland, D.M., MacAyeal, D.R., 2012. Laboratory investigations of iceberg capsize dynamics, energy dissipation and tsunamigenesis. J. Geophys. Res. 117 (F01007).

Chen, F., Heller, V., 2020. Large-scale iceberg-tsunami benchmark test cases. Validation test on SPHERIC website https://spheric-sph.org/validation-tests (under review). 
Chen, F., Heller, V., Briganti, R., 2019. Numerical simulation of tsunamis generated by iceberg calving. Proc. of the $38^{\text {th }}$ IAHR World Congress.

Chen, F., Heller, V., Briganti, R., 2020. Numerical modelling of tsunamis generated by iceberg calving validated with large-scale laboratory experiments. Adv. Water Resour. (under review).

Dean, R.G., Dalrymple, R.A., 2004. Water wave mechanics for engineers and scientists. Advanced series on ocean engineering, Vol. 2, World Scientific, Singapore.

Di Risio, M., Bellotti, G., Panizzo, A., De Girolamo, P., 2009. Three-dimensional experiments on landslide generated waves at a sloping coast. Coast. Eng. 56 (5-6), 659-671.

Dykes, R.C., Brook, M.S., Lube, G., 2016. A major ice-calving event at Tasman Glacier terminus, Southern Alps, 22 February 2011. J. Roy. Soc. New Zeal. 47 (4), 336-343.

Enderlin, E.M., Howat, I.M., Jeong, S., Noh, M.-J., van Angelen, J.H., van den Broeke, M.R., 2014. An improved mass budget for the Greenland ice sheet. Geophys. Res. Lett. 41, 866-872.

Evers, F.M., Hager, W.H., Boes, R.M., 2019a. Spatial impulse wave generation and propagation. J. Waterw. Port C-ASCE 145 (3), 0401901-1-15.

Evers, F.M., Heller, V., Fuchs, H., Hager, W.H., Boes, R.M., 2019b. Landslide generated impulse waves in reservoirs - Basics and computation. $2^{\text {nd }}$ edition. ETH Zurich, Zurich.

Fuchs, H., Boes, R., 2010. Berechnung felsrutschinduzierter Impulswellen im Vierwaldstättersee. Wasser Energie Luft 102 (3), 215-221 (in German).

Fuchs, H., Pfister, M., Boes, R., Perzlmaier, S., Reindl, R., 2011. Impulswellen infolge Lawineneinstoss in den Speicher Kühtai. Wasserwirtschaft 101 (1/2), 54-60 (in German).

Grummel, L., 2018. Linear and nonlinear analysis of ice-generated impulse wave data from 3D wave basin experiments. MSc thesis. University of Brunswick, Brunswick. 
Hanna, E., Navarro, F.J., Pattyn, F., Domingues, C.M., Fettweis, X., Ivins, E.R., Ritz, C., Smith, B., Tulaczyk, S., Whitehouse, P.L., Zwally, H.J., 2013. Ice-sheet mass balance and climate change. Nature 498, 51-59.

Heller, V., 2011. Scale effects in physical hydraulic engineering models. J. Hydraul. Res. 49 (3), 293-306.

Heller, V., 2019a. Tsunamis due to ice masses - Different calving mechanisms and linkage to landslide-tsunamis - Data storage report. Data storage report of HYDRALAB+ test campaign (online http://doi.org/10.5281/zenodo.2556614).

[dataset] Heller, V., 2019b. Tsunamis due to ice masses - Different calving mechanisms and linkage to landslide-tsunamis - Dataset. Dataset of HYDRALAB + test campaign (online http://doi.org/10.5281/zenodo.2554184).

Heller, V., Attili, T., Chen, F., Brühl, M., Gabl, R., Chen, X., Wolters, G., Fuchs, H., 2019a. Large-scale experiments of tsunamis generated by iceberg calving. Proc. of the $38^{\text {th }}$ IAHR World Congress.

Heller, V., Attili, T., Chen, F., Brühl, M., Gabl, R., Chen, X., Wolters, G., Fuchs, H., 2019b. Large-scale iceberg-tsunami experiments. Proc. of the HYDRALAB+ Joint User Meeting, Bucharest, Romania, 67-77, Henry, P.-Y., Breteler M.K. eds.

Heller, V., Chen, F., Brühl, M., Gabl, R., Chen, X., Wolters, G., Fuchs, H., 2019c. Large-scale experiments into the tsunamigenic potential of different iceberg calving mechanisms. Sci. Rep.-UK 9 (861), 1-10.

Heller, V., Hager, W.H., 2010. Impulse product parameter in landslide generated impulse waves. J. Waterw. Port C-ASCE 136 (3), 145-155.

Heller, V., Hager, W.H., 2011. Wave types of landslide generated impulse waves. Ocean Eng. $38(4), 630-640$. 
Heller, V., Hager, W.H., 2014. A universal parameter to predict landslide-tsunamis? J. Mar. Sci. Eng. 2 (2), 400-412.

Heller, V., Hager, W.H., Minor, H.-E., 2008. Scale effects in subaerial landslide generated impulse waves. Exp. Fluids 44 (5), 691-703.

Heller, V., Hager, W.H., Minor, H.-E., 2009. Landslide generated impulse waves in reservoirs - Basics and computation. VAW Mitteilung 211, Boes, R. ed. ETH Zurich, Zurich.

Heller, V., Spinneken, J., 2013. Improved landslide-tsunami predictions: Effects of block model parameters and slide model. J. Geophys. Res.-Oceans 118 (3), 1489-1507.

Heller, V., Spinneken, J., 2015. On the effect of the water body geometry on landslide-tsunamis: Physical insight from laboratory tests and 2D to 3D wave parameter transformation. Coast. Eng. 104 (10), 113-114.

Huber, A., Hager, W.H., 1997. Forecasting impulse waves in reservoirs. Proc. of the 19th Congrès des Grands Barrages, Florence, ICOLD, Paris, pp. 993-1005.

Kranzer, H.C., Keller, J.B., 1959. Water waves produced by explosions. J. Appl. Phys. 30 (3), $398-407$.

Lüthi, M.P., Vieli, A., 2016. Multi-method observation and analysis of a tsunami caused by glacier calving. The Cryosphere 10 (3), 995-1002.

MacAyeal, D.R., Abbot, D.S., Sergienko, O.V., 2011. Iceberg-capsize tsunamigenesis. Ann. Glaciol. 52 (58), 51-56.

MacAyeal, D.R., Okal, E.A., Aster, R.C., Bassis, J.N., 2009. Seismic observations of glaciogenic ocean waves (micro-tsunamis) on icebergs and ice shelves. J. Glaciol. 55 (190), 193-206.

Massel, S.R., Przyborska, A., 2013. Surface wave generation due to glacier calving. Oceanologia 55 (1), 101-127. 
McMillan, M., Leeson, A., Shepherd, A., Briggs, K., Armitage, T.W.K., Hogg, A., Munneke, P.K., van den Broeke, M., Noël, B., van de Berg, W.J., Ligtenberg, S., Horwath, M., Groh, A., Muir, A., Gilbert, L., 2016. A high-resolution record of Greenland mass balance. Geophys. Res. Lett. 43, 7002-7010.

Mendsonboaz, 2009. Tsunami Greenland - Tsunami Groelândia 1995. Online https://www.youtube.com/watch?v=z8LWSOPwkn8 (in German, accessed on 31 May 2020).

Minowa, M., Podolskiy, E.A., Jouvet, G., Weidmann, Y., Sakakibara, D., Tsutaki, S., Genco, R., Sugiyama, S., 2019. Calving flux estimation from tsunami waves. Earth Planet. Sc. Lett. $515,283-290$.

Minowa, M., Podolskiy, E., Sugiyama, S., Sakakibara, D., Skvarca, P., 2018. Glacier calving observed with time-lapse imagery and tsunami waves at Glaciar Perito Moreno, Patagonia. J. Glaciol. 64 (245), 362-376.

Mohammed, F., Fritz, H.M., 2012. Physical modeling of tsunamis generated by threedimensional deformable granular landslides. J. Geophys. Res. 117 (C11015).

Panizzo, A., De Girolamo, P., Petaccia, A., 2005. Forecasting impulse waves generated by subaerial landslides. J. Geophys. Res. 110 (C12025).

Patton, K.T., 1964. Hydrodynamic mass of bodies in a fluid. USL technical memorandum no. 933-351-64, US Navy Underwater Sound Laboratory, Connecticut.

Ruffini, G., Heller, V., Briganti, R., 2019. Numerical modelling of landslide-tsunami propagation in a wide range of idealised water body geometries. Coast. Eng. 153: 103518.

Sorensen, R.M., 1993. Basic wave mechanics for coastal and ocean engineers. Wiley, New York. 
The Guardian, 2018. Huge iceberg threatens tiny Greenland village. Online https://www.theguardian.com/world/2018/jul/14/huge-iceberg-threatens-village-ingreenland (accessed on 31 May 2020).

Todd, J., Christoffersen, P., Zwinger, T., Råback, P., Chauché, N., Benn, D., Luckman, A., Ryan, J., Toberg, N., Slater, D., Hubbard, A., 2018. A full-Stokes 3-D calving model applied to a large Greenlandic glacier. J. Geophys. Res.-Earth 123, 410-432.

Vaňková, I., Holland, D.M., 2016. Calving signature in ocean waves at Helheim Glacier and Sermilik Fjord, East Greenland. J. Phys. Oceanogr. 46 (10), 2925-2941. 
Table 1. Overview of the investigated test parameters of the 66 experiments; The block densities changed slightly with the attachments to the blocks (rod, bearing, etc.); The number of runs indicated with ${ }^{+}$include test repetitions (from H19).

\begin{tabular}{|c|c|c|c|c|c|c|c|c|c|c|c|c|c|}
\hline \multirow{2}{*}{$\frac{\text { Block parameters }}{\text { Block release location }}$} & \multicolumn{3}{|c|}{ Capsizing (mechanism A) } & \multicolumn{6}{|c|}{ Fall (mechanisms B and C) } & \multicolumn{4}{|c|}{ Overturning (mechanisms D and E) } \\
\hline & Offshore & Offshore & Offshore & At shore & At shore & At shore & At shore & At shore & At shore & At shore & At shore & At shore & At shore \\
\hline Block type & 1 & 2 & 2 & 1 & 2 & 1 & 1 & 2 & 2 & 1 & 2 & 2 & 2 \\
\hline Block length $l(\mathrm{~m})$ & 0.800 & 0.800 & 0.500 & 0.800 & 0.800 & 0.500 & 0.500 & 0.500 & 0.500 & 0.800 & 0.800 & 0.500 & 0.500 \\
\hline Block width $b(\mathrm{~m})$ & 0.500 & 0.500 & 0.800 & 0.500 & 0.500 & 0.800 & 0.800 & 0.800 & 0.800 & 0.500 & 0.500 & 0.800 & 0.800 \\
\hline Block thickness $s(\mathrm{~m})$ & 0.500 & 0.250 & 0.250 & 0.500 & 0.250 & 0.500 & 0.500 & 0.250 & 0.250 & 0.500 & 0.250 & 0.250 & 0.250 \\
\hline Block volume $V_{s}\left(\mathrm{~m}^{3}\right)$ & 0.200 & 0.100 & 0.100 & 0.200 & 0.100 & 0.200 & 0.200 & 0.100 & 0.100 & 0.200 & 0.100 & 0.100 & 0.100 \\
\hline $\begin{array}{l}\text { Block density } \rho_{s} \\
\left(\mathrm{~kg} / \mathrm{m}^{3}\right)\end{array}$ & 929 & 924 & 924 & $936 / 923$ & $936 / 912$ & $936 / 923$ & $936 / 923$ & 936/912 & $936 / 912$ & 936/923 & 912 & 912 & 936/912 \\
\hline Mass $m_{s}(\mathrm{~kg})$ & 185.8 & 92.4 & 92.3 & 187.1/184.6 & $93.6 / 91.2$ & $187.1 / 184.6$ & $187.1 / 184.6$ & $93.6 / 91.2$ & 93.6/91.2 & $187.1 / 184.6$ & 91.2 & 91.2 & 93.6/91.2 \\
\hline Water depth $h(\mathrm{~m})$ & 1.000 & 1.000 & 1.000 & 1.000 & 1.000 & 1.000 & 0.750 & 1.000 & 0.750 & 1.000 & 1.000 & 1.000 & 0.750 \\
\hline $\begin{array}{l}\text { Release position above } \\
\text { still water level (m) }\end{array}$ & $\begin{array}{c}\text { Neutrally } \\
\text { buoyant }\end{array}$ & $\begin{array}{c}\text { Neutrally } \\
\text { buoyant }\end{array}$ & $\begin{array}{c}\text { Neutrally } \\
\text { buoyant }\end{array}$ & $\begin{array}{l}0.00,-0.30 \\
-0.60,-0.84\end{array}$ & $\begin{array}{l}0.00,-0.30 \\
-0.60,-0.83\end{array}$ & $\begin{array}{c}0.30,0.00 \\
-0.30,-0.60 \\
-0.70,-0.83\end{array}$ & $\begin{array}{l}0.30,0.00 \\
-0.30 \\
-0.60\end{array}$ & $\begin{array}{c}0.30,0.00 \\
-0.30,-0.60 \\
-0.83\end{array}$ & $\begin{array}{l}0.30,0.00 \\
-0.30 \\
-0.60\end{array}$ & $\begin{array}{c}0.15,0.00 \\
-0.30,-0.60 \\
-0.90\end{array}$ & $\begin{array}{c}0.15,0.00 \\
-0.30,-0.60 \\
-0.90\end{array}$ & $\begin{array}{l}0.15,0.00 \\
\quad-0.30 \\
-0.60\end{array}$ & $\begin{array}{l}0.15,0.00 \\
-0.30 \\
-0.60\end{array}$ \\
\hline Number of runs & $5^{+}$ & $6^{+}$ & $5^{+}$ & $6^{+}$ & 4 & $7^{+}$ & 4 & 5 & 4 & 5 & 5 & 4 & $6^{+}$ \\
\hline
\end{tabular}


Table 2. Governing dimensional (top) and dimensionless (bottom) parameters with experimental ranges.

\begin{tabular}{cccc}
\hline Symbol & Unit & Description & Experimental range \\
\hline$E$ & {$[\mathrm{~J}]$} & Released energy & $5.68-979.48$ \\
$h$ & {$[\mathrm{~m}]$} & Water depth & $0.75,1.00$ \\
$V_{s}$ & {$[\mathrm{~m} / \mathrm{s}]$} & Iceberg velocity & $0.27-4.17$ \\
$s$ & {$[\mathrm{~m}]$} & Iceberg thickness & $0.25,0.50$ \\
$b$ & {$[\mathrm{~m}]$} & Iceberg width & $0.50,0.80$ \\
$\forall_{s}$ & {$\left[\mathrm{~m}^{3}\right]$} & Iceberg volume & $0.10,0.20$ \\
$\rho_{s}$ & {$\left[\mathrm{~kg} / \mathrm{m}^{3}\right]$} & Iceberg density & $911.50-936.20$ \\
$\rho_{w}$ & {$\left[\mathrm{~kg} / \mathrm{m}^{3}\right]$} & Water density & 1000 \\
$g$ & {$\left[\mathrm{~m} / \mathrm{s}^{2}\right]$} & Gravitational acceleration & 9.81 \\
$E_{r}=E /\left(h^{4} g \rho_{w}\right)$ & {$[-]$} & Relative released energy & $0.0006-0.3157$ \\
$\mathrm{~F}=V_{s} /(g h)^{1 / 2}$ & {$[-]$} & Froude number & $0.09-1.33$ \\
$S=s / h$ & {$[-]$} & Relative iceberg thickness & $0.25-0.67$ \\
$B=b / h$ & {$[-]$} & Relative iceberg width & $0.50-1.07$ \\
$V=\forall_{s} / h^{3}$ & {$[-]$} & Relative iceberg volume & $0.10-0.47$ \\
$D=\rho_{s} / \rho_{w}$ & {$[-]$} & Relative density & $0.91-0.94$ \\
\hline & & &
\end{tabular}

Table 3. Names and locations of wave probes and cameras (from Heller, 2019a).

\begin{tabular}{|c|c|c|c|}
\hline $\begin{array}{l}\text { Iceberg } \\
\text { calving } \\
\text { mechanism }\end{array}$ & Device & $\begin{array}{l}\text { Water } \\
\text { depth } h \\
\text { (m) }\end{array}$ & $\begin{array}{l}\text { Locations in function of the radial distance } r(\mathrm{~m}) \text { and the wave } \\
\text { propagation angle } \gamma\left({ }^{\circ}\right) \text { (Fig. 3a,c) }\end{array}$ \\
\hline Capsizing & $\begin{array}{l}\text { Wave } \\
\text { probes }\end{array}$ & 1.000 & $\begin{array}{l}\text { A1 }(2,0) ; \text { A10 }(3,0) ; \text { A19 }(5,0) ; \text { A28 }(10,0) ; \text { A32 }(15,0) ; \\
\text { A2 }(2,-15) ; \text { A11 }(3,-15) ; \text { A20 }(5,-15) ; \text { A29 }(10,-15) ; \\
\text { A3 }(2,-30) ; \text { A12 }(3,-30) ; \text { A21 }(5,-30) ; \\
\text { A4 }(2,-60) ; \text { A13 }(3,-60) ; \text { A22 }(5,-60) ; \\
\text { A5 }(2,-90) ; \text { A14 }(3,-90) ; \text { A23 }(5,-90) ; \\
\text { A6 }(2,-120) ; \text { A15 }(3,-120) ; \text { A24 }(5,-120) ; \\
\text { A7 }(2,-15) ; \text { A16 }(3,-150) ; \text { A25 }(5,-150) ; \\
\text { A8 }(2,-165) ; \text { A17 }(3,-165) ; \text { A26 }(5,-165) ; \text { A30 }(10,-165) ; \\
\text { A9 }(2,-180) ; \text { A18 }(3,-180) ; \text { A27 }(5,-180) ; \text { A31 }(10,-180) ; \text { A33 }(15,-180)\end{array}$ \\
\hline Capsizing & Cameras & 1.000 & $5 \mathrm{MP}$ at $15 \mathrm{~Hz}:(6,-45) ; 2 \mathrm{MP}$ at $100 \mathrm{~Hz}:(6,-95)$ \\
\hline $\begin{array}{l}\text { Fall/ } \\
\text { overturning }\end{array}$ & $\begin{array}{l}\text { Wave } \\
\text { probes }\end{array}$ & 1.000 & 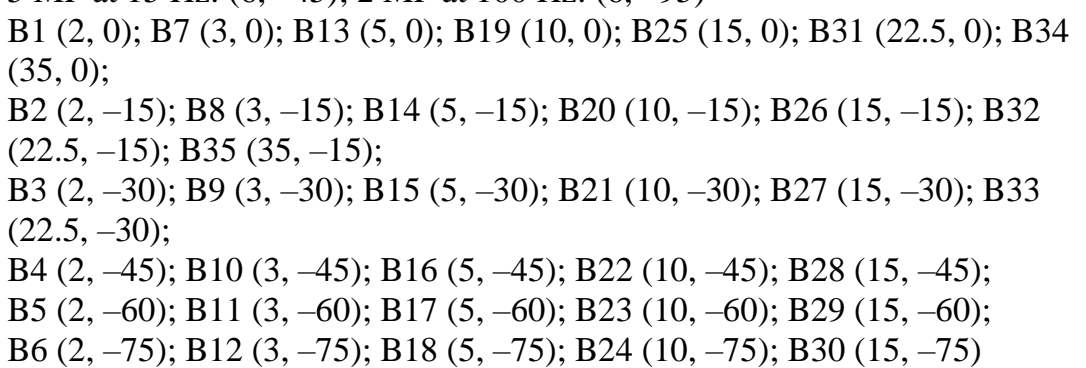 \\
\hline $\begin{array}{l}\text { Fall/ } \\
\text { overturning }\end{array}$ & $\begin{array}{l}\text { Wave } \\
\text { probes }\end{array}$ & 0.750 & $\begin{array}{l}\text { C1 }(1.5,0) ; \text { C } 7(2.25,0) ; \text { C } 13(3.75,0) ; \text { C } 19(7.5,0) ; \text { C } 25(11.25,0) ; \mathrm{C} 31 \\
(16.875,0) ; \text { C } 34(26.25,0) ; \\
\text { C2 }(1.5,-15) ; \text { C } 8(2.25,-15) ; \text { C } 14(3.75,-15) ; \text { C } 20(7.5,-15) ; \text { C } 26(11.25 \text {, } \\
-15) ; \text { C } 32(16.875,-15) ; \text { C } 35(26.25,-15) ;\end{array}$ \\
\hline
\end{tabular}


C3 (1.5, -30); C9 (2.25, -30); C15 (3.75, -30); C21 (7.5, -30); C27 (11.25,

$-30)$; C33 (16.875, -30);

C4 (1.5, -45); C10 (2.25, -45); C16 (3.75, -45); C22 (7.5, -45); C28 (11.25, $-45)$

C5 (1.5, -60); C11 (2.25, -60); C17 (3.75, -60); C23 (7.5, -60); C29 (11.25, $-60)$

C6 (1.5, -75); C12 (2.25, -75); C18 (3.75, -75); C24 (7.5, -75); C30 (11.25, $-75)$

Fall/ Cameras $1.000 \quad 2 \mathrm{MP}$ at $100 \mathrm{~Hz}:(6,-85) ; 5 \mathrm{MP}$ at $15 \mathrm{~Hz}(6,45)$

overturning and

0.750

Table 4. Maximum values of the wave height $H_{M}$, amplitude $a_{M}$ and the period $T_{M}$ corresponding to $H_{M}$ for each iceberg-calving mechanism in dimensional and dimensionless form.

\begin{tabular}{cccccc}
\hline & Capsizing & $\begin{array}{l}\text { Gravity- } \\
\text { dominated } \\
\text { fall }\end{array}$ & $\begin{array}{l}\text { Buoyancy- } \\
\text { dominated } \\
\text { fall }\end{array}$ & $\begin{array}{l}\text { Gravity- } \\
\text { dominated } \\
\text { overturning }\end{array}$ & $\begin{array}{l}\text { Buoyancy- } \\
\text { dominated } \\
\text { overturning }\end{array}$ \\
\hline$H_{M}[\mathrm{~m}]$ & 0.015 & 0.119 & 0.016 & 0.118 & 0.008 \\
$H_{M} / h[-]$ & 0.015 & 0.158 & 0.020 & 0.157 & 0.008 \\
$a_{M}[\mathrm{~m}]$ & 0.009 & 0.068 & 0.011 & 0.091 & 0.0051 \\
$a_{M} / h[-]$ & 0.009 & 0.072 & 0.011 & 0.122 & 0.0051 \\
$T_{M}[\mathrm{~s}]$ & 0.89 & 2.12 & 1.99 & 2.24 & 2.03 \\
$T_{M}(g / h)^{1 / 2}[-]$ & 2.79 & 6.94 & 6.23 & 7.02 & 6.36 \\
\hline
\end{tabular}

Table 5. Governing parameters of the 2014 Eqip Sermia Glacier event (data from Lüthi and Vieli, 2016).

\begin{tabular}{cccc}
\hline Symbol & Unit & Description & Eqip Sermia 2014 \\
\hline$h$ & {$[\mathrm{~m}]$} & Water depth & 30 \\
$l$ & {$[\mathrm{~m}]$} & Iceberg length & 200 \\
$b$ & {$[\mathrm{~m}]$} & Iceberg width & 90 \\
$s$ & {$[\mathrm{~m}]$} & Iceberg thickness & 50 \\
$V_{s}$ & {$[\mathrm{~m} / \mathrm{s}]$} & Iceberg velocity & 34.8 \\
$z_{c}$ & {$[\mathrm{~m}]$} & Initial position of the iceberg & 100 \\
$E$ & {$[\mathrm{~J}]$} & centroid & $7.2 \times 10^{11}$ \\
$V_{s}$ & {$\left[\mathrm{~m}^{3}\right]$} & Released energy & $9.0 \times 10^{5}$ \\
$\rho_{s}$ & {$\left[\mathrm{~kg} / \mathrm{m}^{3}\right]$} & Iceberg volume & 900 \\
$\rho_{w}$ & {$\left[\mathrm{~kg} / \mathrm{m}^{3}\right]$} & Iceberg density & 1000 \\
$E_{r}$ & {$[-]$} & Water density & 90.0 \\
$\mathrm{~F}$ & {$[-]$} & Relative released energy & 2.03
\end{tabular}




\begin{tabular}{cccc}
$V$ & {$[-]$} & Relative iceberg volume & 33.3 \\
$S$ & {$[-]$} & Relative iceberg thickness & 1.67 \\
$B$ & {$[-]$} & Relative iceberg width & 3.00 \\
$D$ & {$[-]$} & Relative density & 0.90 \\
$a_{\text {meas }}$ & {$[\mathrm{m}]$} & Measured wave amplitude & $45-50$ \\
$a_{\text {pred }}$ & {$[\mathrm{m}]$} & Predicted wave amplitude & 36 \\
\hline
\end{tabular}

Table A.1. Iceberg velocities $V_{s}$ for different calving mechanisms. The symbols are explained in the notation.

\begin{tabular}{|c|c|c|c|c|}
\hline $\begin{array}{l}\text { Iceberg calving } \\
\text { mechanism }\end{array}$ & $\begin{array}{l}\text { Initial } \\
\text { position of the } \\
\text { iceberg }\end{array}$ & $V_{s}$ & Basic assumptions & References \\
\hline Capsizing (A) & & {$\left[\left(1-\rho_{s} / \rho_{w}\right) g l(1-s / l)\right]^{1 / 2}$} & $E_{k}=E$ & $\begin{array}{l}\text { Burton et } \\
\text { al. (2012) }\end{array}$ \\
\hline \multirow[t]{2}{*}{$\begin{array}{l}\text { Gravity- } \\
\text { dominated fall } \\
\text { (B) }\end{array}$} & $z_{c}>l / 2$ & $\left(m_{s} V_{b}\right) /\left(m_{s}+M_{s}\right)$ & $\begin{array}{c}V_{b}=\left[2 g z_{c}(1-\right. \\
f \operatorname{cotg} \alpha)]^{1 / 2} \\
M_{s}=1 / 4 \pi \rho_{w} b s^{2} C_{M} \\
\text { with coefficient } \\
C_{M} \text { tabulated in } \\
\text { Patton }(1964) \text { for } \\
\text { rectangular plates } \\
\text { of different ratios } \\
\text { of } b / s\end{array}$ & $\begin{array}{l}\text { Massel and } \\
\text { Przyborska } \\
\text { (2013) } \\
\text { Patton } \\
(1964)\end{array}$ \\
\hline & $\begin{array}{c}l\left(1 / 2-\rho_{s} / \rho_{w}\right) \\
\quad<z_{c} \leq l / 2\end{array}$ & {$\left[2 g\left(\forall_{s} \rho_{s}-\forall_{s, \text { sub }} \rho_{w}\right) /\left(\rho_{w} C_{d, f r i c} A\right)\right]^{1 / 2}$} & $\begin{array}{l}\text { Balance equation: } \\
\qquad F_{g}-F_{b}-R= \\
\quad m_{s} d V / d t \\
\text { Resistance: } \\
\text { friction with } C_{d, \text { fric }} \\
=0.50 \text { and inertia } \\
\text { with } C_{a}=0.25\end{array}$ & $\begin{array}{l}\text { Massel and } \\
\text { Przyborska } \\
(2013)\end{array}$ \\
\hline \multirow[t]{2}{*}{$\begin{array}{l}\text { Buoyancy- } \\
\text { dominated fall } \\
\text { (C) }\end{array}$} & $z_{c}<-l / 2$ & $\begin{array}{c}{\left[2 \forall_{s}\left(\rho_{w}-\rho_{s}\right) g /\left(\rho_{w} C_{d} A_{H}\right)\right]^{1 / 2}} \\
\tanh \left(2 e_{0} / m_{s} V_{s}\left[\rho_{w} C_{d} A_{H} \forall_{s}\left(\rho_{w}-\right.\right.\right. \\
\left.\left.\left.\rho_{s}\right) g / 2\right]^{1 / 2}\right)\end{array}$ & $\begin{array}{l}\text { Balance equation: } \\
\qquad F_{b}-F_{g}-R= \\
\quad m_{s} d V / d t \\
\text { Resistance: drag }\end{array}$ & $\begin{array}{l}\text { Attili } \\
(2019)\end{array}$ \\
\hline & $\begin{array}{c}-l / 2<z_{c} \leq \\
l\left(1 / 2-\rho_{s} / \rho_{w}\right)\end{array}$ & {$\left[2 g\left(\forall_{s, s u b} \rho_{w}-\forall_{s} \rho_{s}\right) /\left(\rho_{w} C_{d, f r i c} A\right)\right]^{1 / 2}$} & $\begin{array}{l}\text { Balance equation: } \\
\qquad F_{b}-F_{g}-R= \\
\quad m_{s} d V / d t \\
\text { Resistance: } \\
\text { friction with } C_{d, \text { fric }} \\
=0.50 \text { and inertia } \\
\text { with } C_{a}=0.25\end{array}$ & $\begin{array}{l}\text { Attili } \\
\text { (2019) }\end{array}$ \\
\hline $\begin{array}{l}\text { Gravity- } \\
\text { dominated } \\
\text { overturning (D) }\end{array}$ & & $\left(m_{s} \omega_{D} l\right) /\left(m_{s}+M_{s}\right)$ & $\begin{array}{c}\omega_{D} \text { is estimated } \\
\text { with Eq. (A.1) }\end{array}$ & $\begin{array}{l}\text { Massel and } \\
\text { Przyborska } \\
(2013)\end{array}$ \\
\hline $\begin{array}{l}\text { Buoyancy- } \\
\text { dominated } \\
\text { overturning (E) }\end{array}$ & & $\omega_{E} l$ & $\begin{array}{l}\omega_{E} \text { is estimated } \\
\text { with Eq. (A.2) }\end{array}$ & $\begin{array}{l}\text { Massel and } \\
\text { Przyborska } \\
\text { (2013) }\end{array}$ \\
\hline
\end{tabular}


Table C.1. Dimensionless parameters of the present IBTs and 3D SLT studies.

\begin{tabular}{|c|c|c|c|c|c|c|c|c|}
\hline Study & $\mathrm{F}[-]$ & $S[-]$ & $B[-]$ & $M[-]$ & $D[-]$ & $P[-]$ & $\alpha\left[^{\circ}\right]$ & $r / h[-]\left(\gamma\left[^{\circ}\right]\right)$ \\
\hline $\begin{array}{l}\text { Present } \\
\text { study }\end{array}$ & $\begin{array}{c}0.09- \\
1.33\end{array}$ & $\begin{array}{c}0.25- \\
0.67\end{array}$ & $\begin{array}{c}0.50- \\
1.07\end{array}$ & $\begin{array}{c}0.11- \\
0.42\end{array}$ & $\begin{array}{c}0.91- \\
0.94\end{array}$ & $\begin{array}{c}0.01- \\
0.32\end{array}$ & 90 & $\begin{array}{c}2.0-35.0(0- \\
-15) \\
2.0-22.5(-30) \\
2.0-15.0(-75- \\
-45)\end{array}$ \\
\hline $\begin{array}{c}\text { Huber and } \\
\text { Hager } \\
(1997)\end{array}$ & $\begin{array}{l}1.06- \\
1.84\end{array}$ & - & $\begin{array}{c}1.39- \\
4.17\end{array}$ & - & $\begin{array}{l}0.92- \\
2.70\end{array}$ & - & $\begin{array}{c}28- \\
60\end{array}$ & $\begin{array}{c}5.0-30.0(-90- \\
90)\end{array}$ \\
\hline $\begin{array}{l}\text { Panizzo et } \\
\text { al. }(2005)\end{array}$ & $\begin{array}{l}1.00- \\
2.22\end{array}$ & $\begin{array}{l}0.11- \\
0.45\end{array}$ & $\begin{array}{c}0.38- \\
1.50\end{array}$ & - & 2.20 & - & $\begin{array}{l}16- \\
36\end{array}$ & $\begin{array}{c}1.3-15.1(0- \\
30) \\
1.3-15.1(60- \\
90)\end{array}$ \\
\hline $\begin{array}{l}\text { Heller et al. } \\
\text { (2009) }\end{array}$ & $\begin{array}{c}0.86- \\
6.83\end{array}$ & $\begin{array}{c}0.09- \\
1.64\end{array}$ & $\begin{array}{c}0.74- \\
3.33\end{array}$ & $\begin{array}{l}0.11- \\
10.02\end{array}$ & $\begin{array}{c}0.59- \\
1.72\end{array}$ & $\begin{array}{l}0.17- \\
8.13\end{array}$ & $\begin{array}{c}30 \text { to } \\
90\end{array}$ & $\begin{array}{c}5.0-30.0(-90- \\
90)\end{array}$ \\
\hline $\begin{array}{l}\text { Mohammed } \\
\text { and Fritz } \\
(2012)\end{array}$ & 1 to 4 & $\begin{array}{c}0.1 \text { to } \\
0.9\end{array}$ & 1 to 7 & - & 1.76 & - & 27.1 & $\begin{array}{c}8.5-40.2(0) \\
8.6-40.3(5) \\
8.8-24.0(13) \\
9.1-25.0(21) \\
7.5-16.4(30) \\
9.2-12.1(45) \\
13.0-17.1(60)\end{array}$ \\
\hline $\begin{array}{l}\text { Heller and } \\
\text { Spinneken } \\
\text { (2015) }\end{array}$ & $\begin{array}{l}0.54- \\
2.47\end{array}$ & $\begin{array}{c}0.25- \\
0.50\end{array}$ & $\begin{array}{l}1.20- \\
2.40\end{array}$ & $\begin{array}{c}0.25- \\
2.49\end{array}$ & $\begin{array}{l}1.45- \\
1.60\end{array}$ & $\begin{array}{c}0.16- \\
1.56\end{array}$ & 45 & $\begin{array}{c}3.0-35.0(0- \\
73)\end{array}$ \\
\hline $\begin{array}{l}\text { Evers et al. } \\
\text { (2019a) }\end{array}$ & $\begin{array}{c}0.40- \\
3.40\end{array}$ & $\begin{array}{c}0.15- \\
0.60\end{array}$ & $\begin{array}{c}0.83- \\
5.00\end{array}$ & $\begin{array}{c}0.25- \\
1.00\end{array}$ & 1.34 & $\begin{array}{l}0.13- \\
2.08\end{array}$ & $\begin{array}{c}30- \\
90\end{array}$ & $\begin{array}{c}1.1-16.3(0- \\
90)\end{array}$ \\
\hline
\end{tabular}



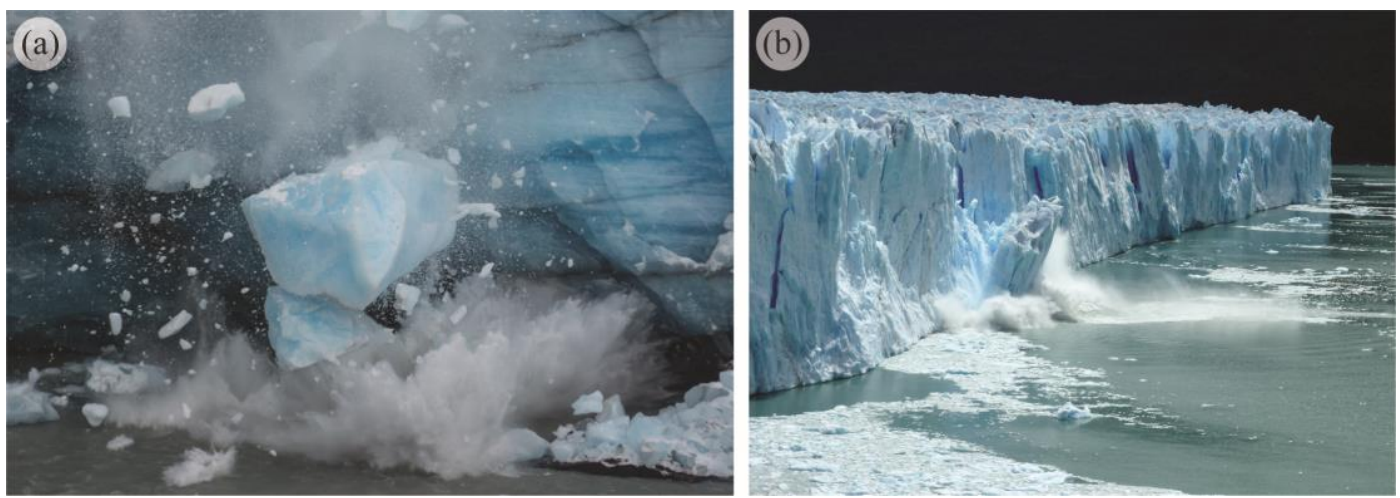

Fig. 1. Iceberg calving in nature at Perito Moreno Glacier, Argentina: (a) falling iceberg (photo courtesy of Alex Cowan) and (b) overturning iceberg (photo courtesy of Michael Schwab).

A: Capsizing

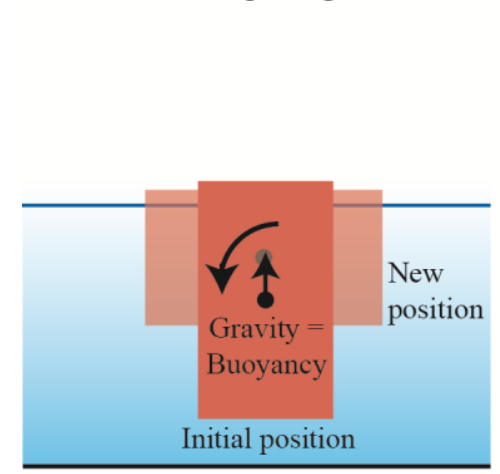

Fall

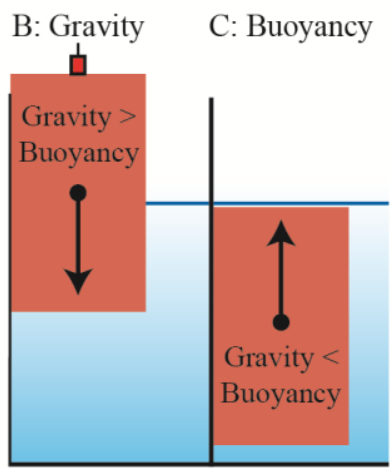

Overturning

D: Gravity

E: Buoyancy

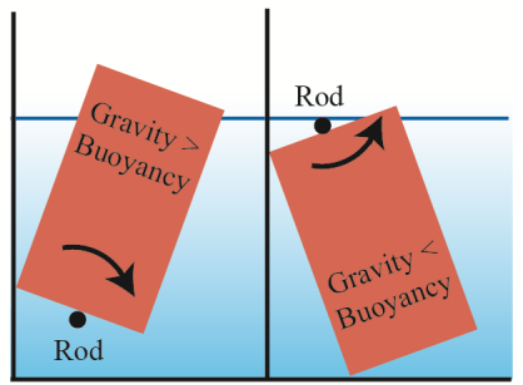

Fig. 2. Sketches of investigated iceberg calving mechanisms from left to right: A: capsizing, B: gravity-dominated fall, C: buoyancy-dominated fall, D: gravity-dominated overturning and E: buoyancy-dominated overturning (adapted from H19). 




(b)
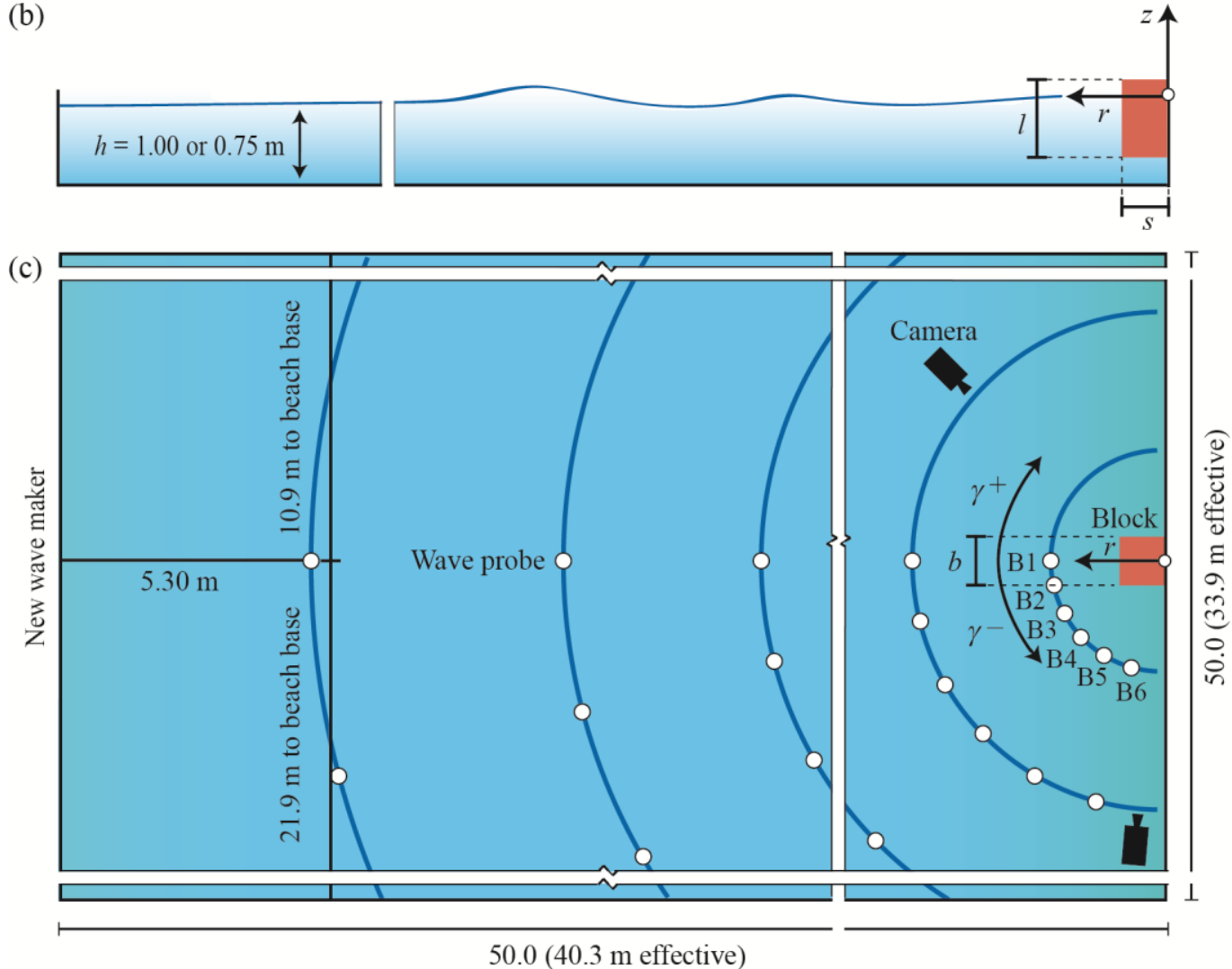

Fig. 3. Schematics of experimental set-up: (a) plan view of a capsizing experiment and (b) side view and (c) plan view of a gravity-dominated fall experiment. The wave probe locations are given in Table 3 (adapted from H19). 

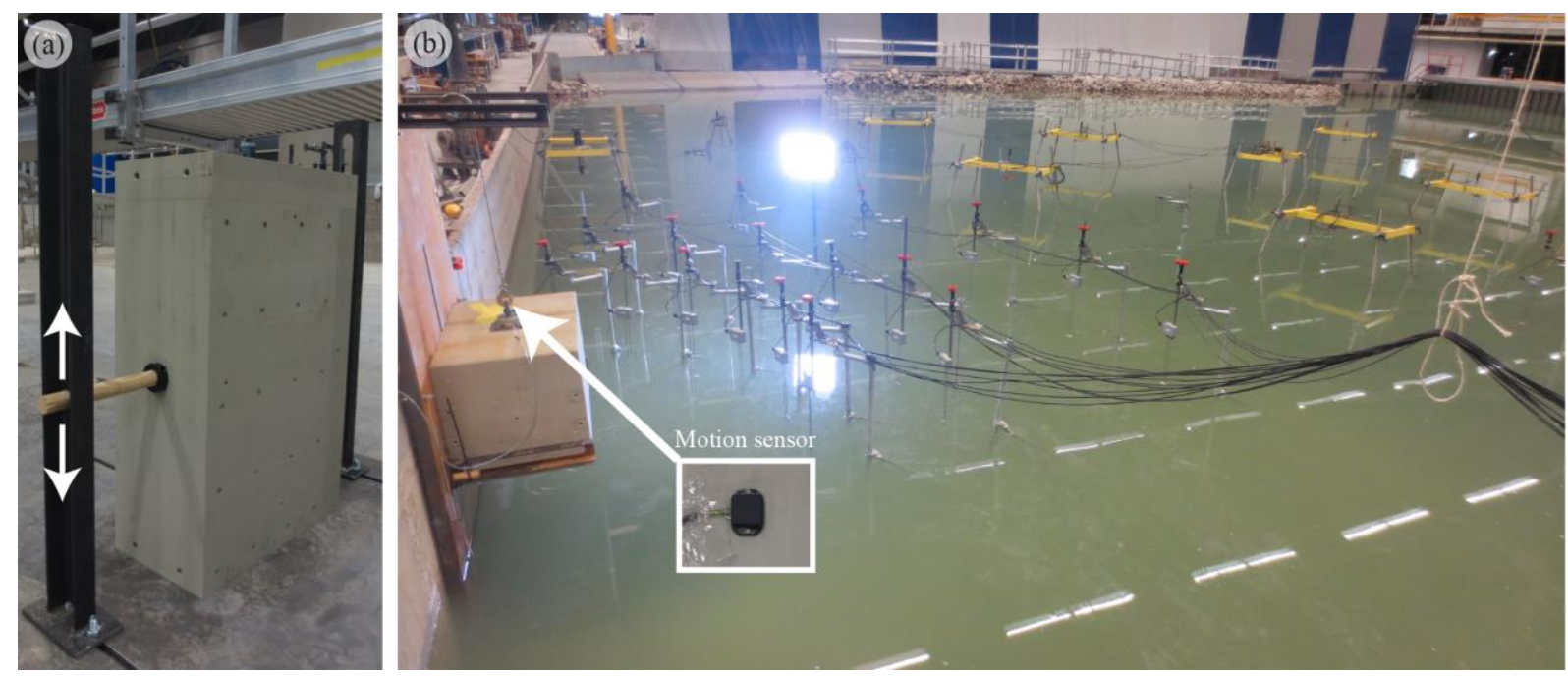

Fig. 4. Pictures of experiments in the $50 \mathrm{~m} \times 50 \mathrm{~m}$ wave basin: (a) iceberg block type 2 $(0.800 \mathrm{~m} \times 0.500 \mathrm{~m} \times 0.250 \mathrm{~m})$ located next to the duckboard in preparation for a capsizing experiment (mechanism A) prior to filling the basin and (b) iceberg block type $1(0.800 \mathrm{~m} \times 0.500 \mathrm{~m} \times 0.500 \mathrm{~m})$ in the gravity-dominated fall release position (mechanism B) at the basin wall with most of the 35 wave probes shown. The inset shows the motion sensor attached to the block surface.

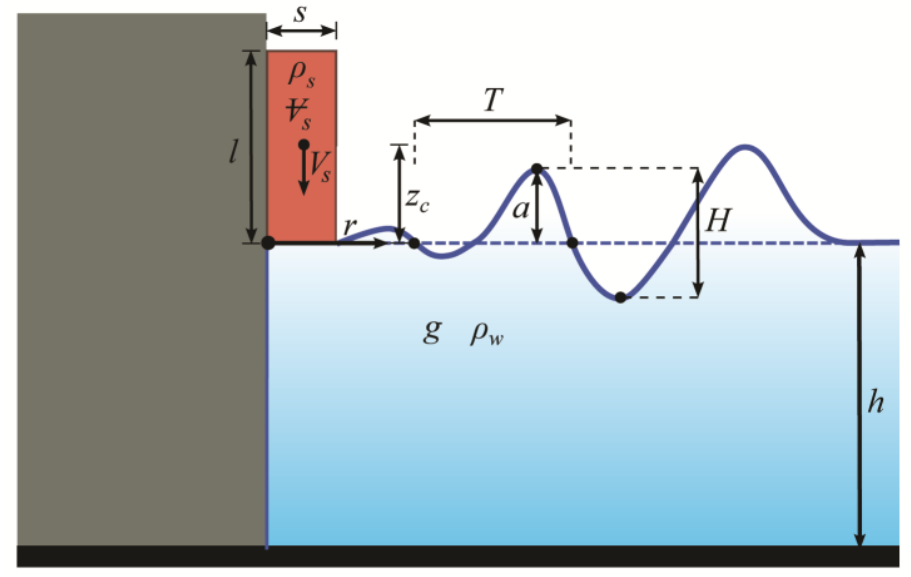

Fig. 5. Schematic view of the gravity-dominated fall mechanism with definition of the governing and wave parameters. 




(c)

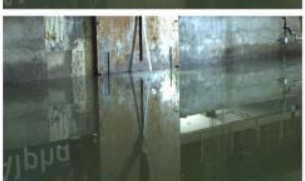

(d)

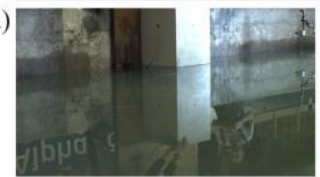

(e)

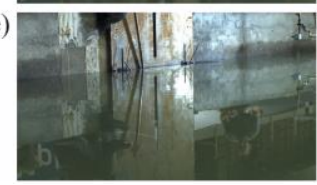


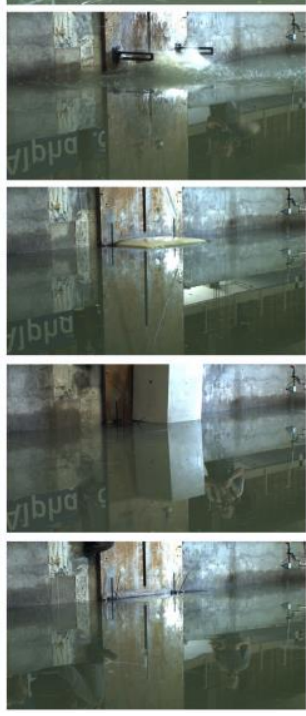
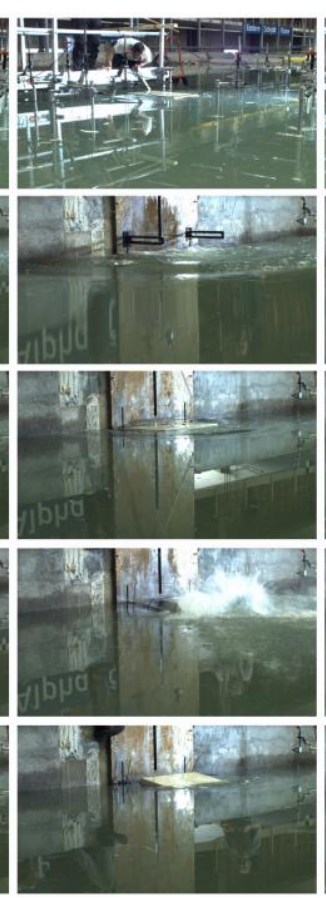
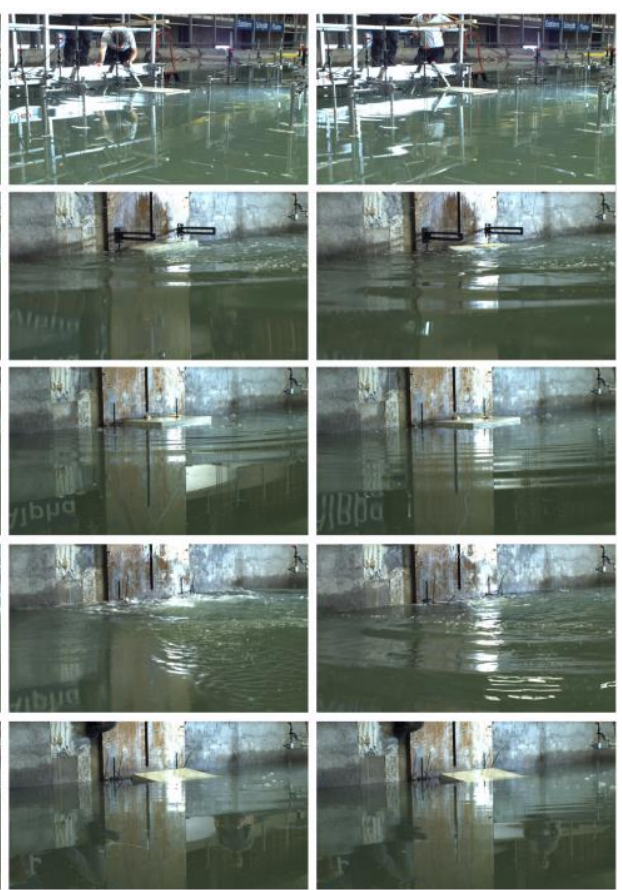

Fig. 6. Image series of experiments conducted at $h=1.00 \mathrm{~m}$ : (a) mechanism A, (b) B, (c) C, (d) D and (e) E. The shown examples of mechanisms A, B and E were conducted with the $0.800 \mathrm{~m} \times 0.500 \mathrm{~m} \times 0.250 \mathrm{~m}$ block (type 2 ) and the examples of mechanisms $\mathrm{C}$ and $\mathrm{D}$ with the $0.800 \mathrm{~m} \times 0.500 \mathrm{~m} \times 0.500 \mathrm{~m}$ block (type 1 ). The time intervals between the images are $2.67 \mathrm{~s}$ for (a) and (e) and $1.33 \mathrm{~s}$ for (b) to (d).
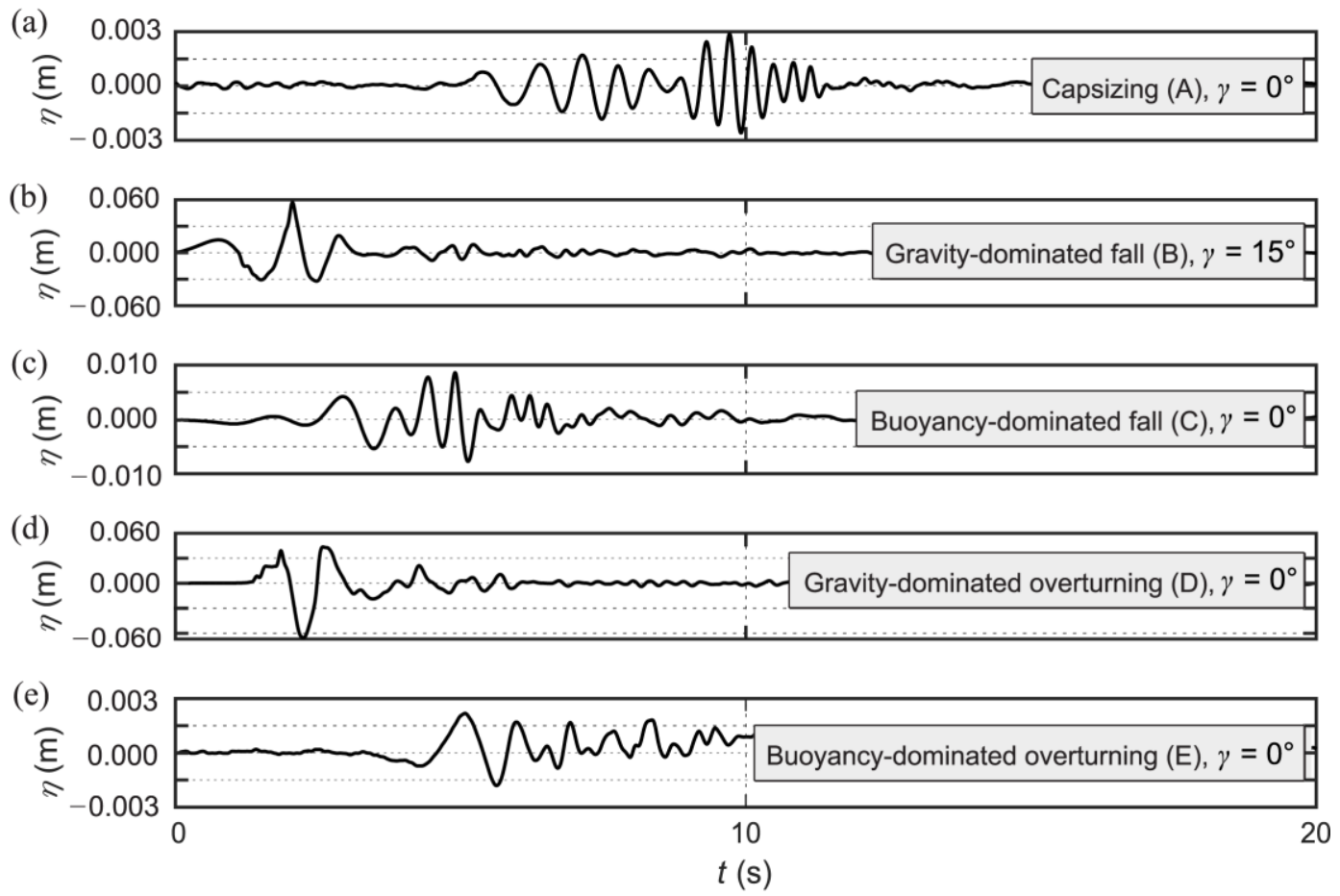
Fig. 7. IBT profiles of the five iceberg calving mechanisms A to E in Fig. 6. These tsunami profiles were recorded at $(r / h=2, \gamma)$ where the maximum wave height $H_{M}$ was measured. (a) mechanism A, (b) B, (c) C, (d) D and (e) E. The scale on the y-axes change by up to a factor of 20 . 

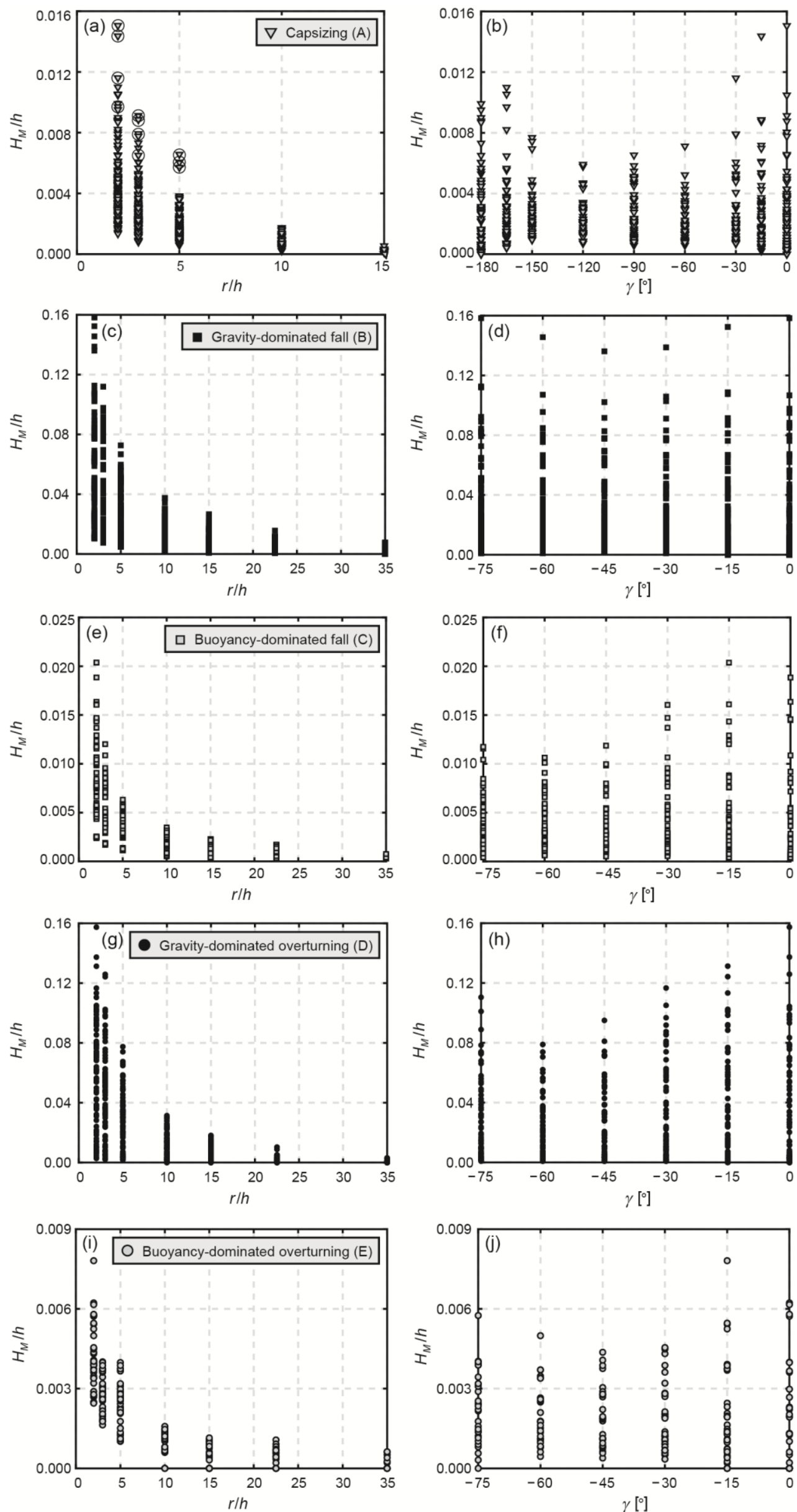
Fig. 8. Overview of the maximum relative wave height $H_{M} / h$ decay for all experiments with $(\mathrm{a}, \mathrm{c}, \mathrm{e}, \mathrm{g}, \mathrm{i})$ the relative distance $r / h$ and $(\mathrm{b}, \mathrm{d}, \mathrm{f}, \mathrm{h}, \mathrm{j})$ the wave propagation angle $\gamma \cdot(\mathrm{a}, \mathrm{b})$ capsizing (mechanism A) with the 11 largest outliers from the two harder pushed experiments encircled, (c,d) gravity-dominated fall (B), (e,f) buoyancy-dominated fall (C), (g,h) gravity-dominated overturning (D) and $(\mathrm{i}, \mathrm{j})$ buoyancy-dominated overturning (E). 

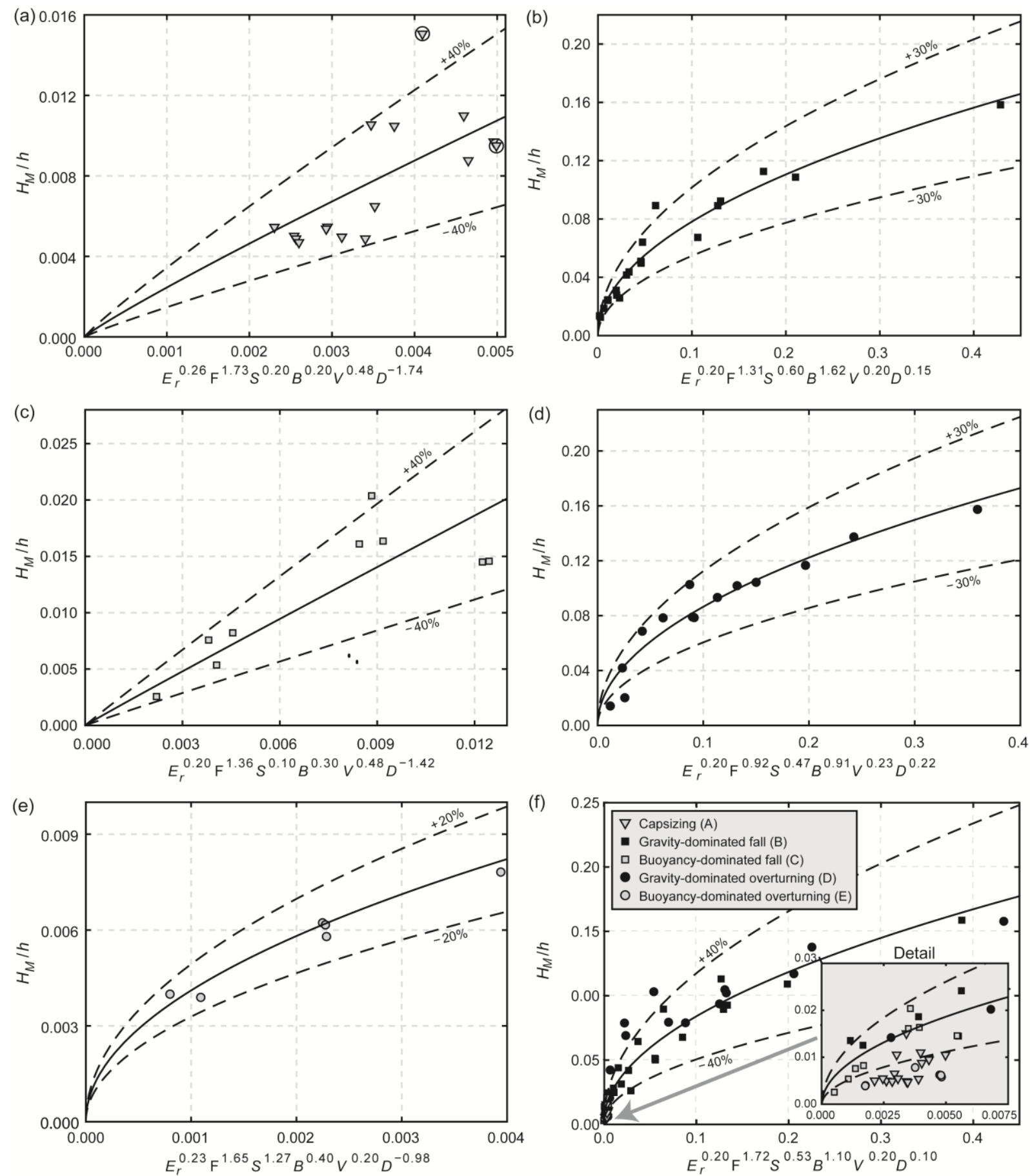

Fig. 9. Maximum relative wave height $H_{M} / h$ versus a dimensionless parameter combination: (a) mechanism A with (-) Eq. (3) (--) $\pm 40 \%$ deviation $\left(R^{2}=0.49\right)$ and the data points of the two harder pushed experiments encircled, (b) mechanism B with (-) Eq. (4) (-) $\pm 30 \%$ deviation $\left(R^{2}=0.95\right)$, (c) mechanism C with (-) Eq. (5) $(--) \pm 40 \%$ deviation $\left(R^{2}=0.64\right),(\mathrm{d})$ mechanism D with $(-)$ Eq. (6) $(--) \pm 30 \%$ deviation $\left(R^{2}=0.92\right),(\mathrm{e})$ 
mechanism E with (-) Eq. (7) (--) $\pm 20 \%$ deviation $\left(R^{2}=0.95\right)$ and (f) all mechanisms with (-) Eq. (8) (--) $\pm 40 \%$ deviation $\left(R^{2}=0.92\right)$. For the notation see (f).
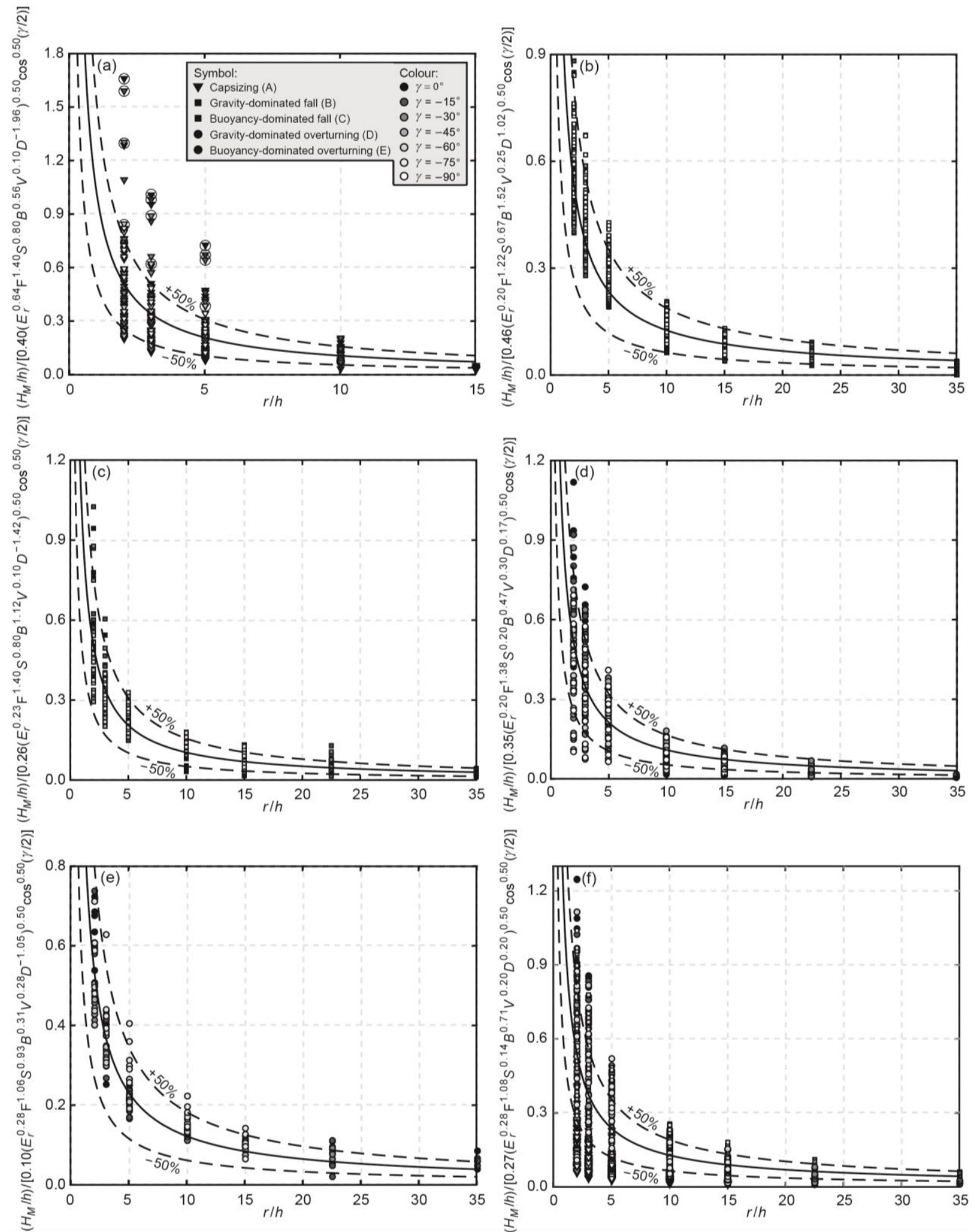
Fig. 10. Normalised relative maximum wave height $H_{M} / h$ decay for all experiments with the relative distance $r / h$ : (a) mechanism A with (-) Eq. (9) $(--) \pm 50 \%$ deviation $\left(R^{2}=\right.$ 0.40) and the 11 largest outliers from the two harder pushed experiments encircled, (b) mechanism B with (-) Eq. (10) $(--) \pm 50 \%$ deviation $\left(R^{2}=0.93\right),(\mathrm{c})$ mechanism C with (-) Eq. (11) (--) $\pm 50 \%$ deviation $\left(R^{2}=0.84\right),($ d) mechanism D with $(-)$ Eq. (12) (--) $\pm 50 \%$ deviation $\left(R^{2}=0.86\right)$, (e) mechanism E with (-) Eq. (13) (--) $\pm 50 \%$ deviation $\left(R^{2}=0.89\right)$ and (f) all mechanisms with (-) Eq. (14) $(--) \pm 50 \%$ deviation $\left(R^{2}=0.80\right)$. For the notation see (a).
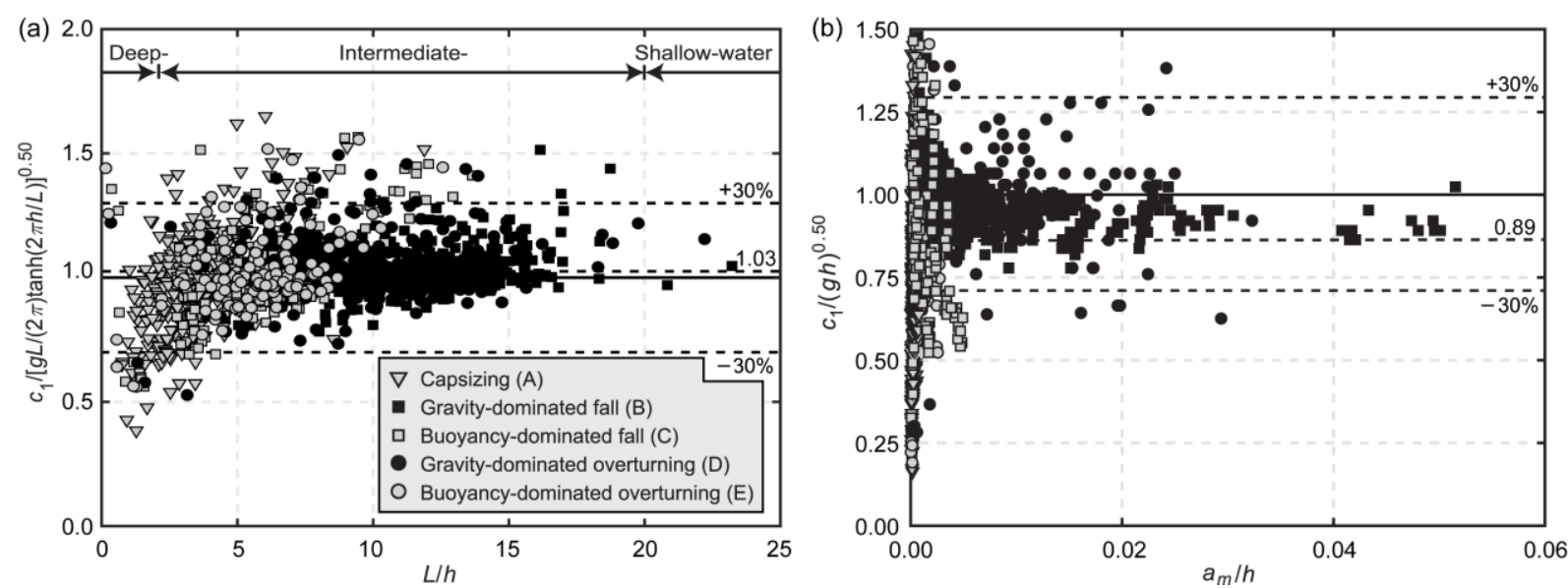

Fig. 11. First wave celerity between two subsequent wave probes: (a) mean first wave celerity $c_{1} /[g L /(2 \pi) \tanh (2 \pi h / L)]^{1 / 2}$, normalised with the general linear wave celerity, versus the relative wavelength $L / h$ with $(-)$ Eq. (15) $\left(R^{2}=-0.03\right)$ and (b) mean relative first wave celerity $c_{1} /(g h)^{1 / 2}$, normalised with the linear shallow-water wave celerity, versus the mean relative wave amplitude $a_{m} / h$ with $(-)$ Eq. (16) $\left(R^{2}=-0.34\right)$. 

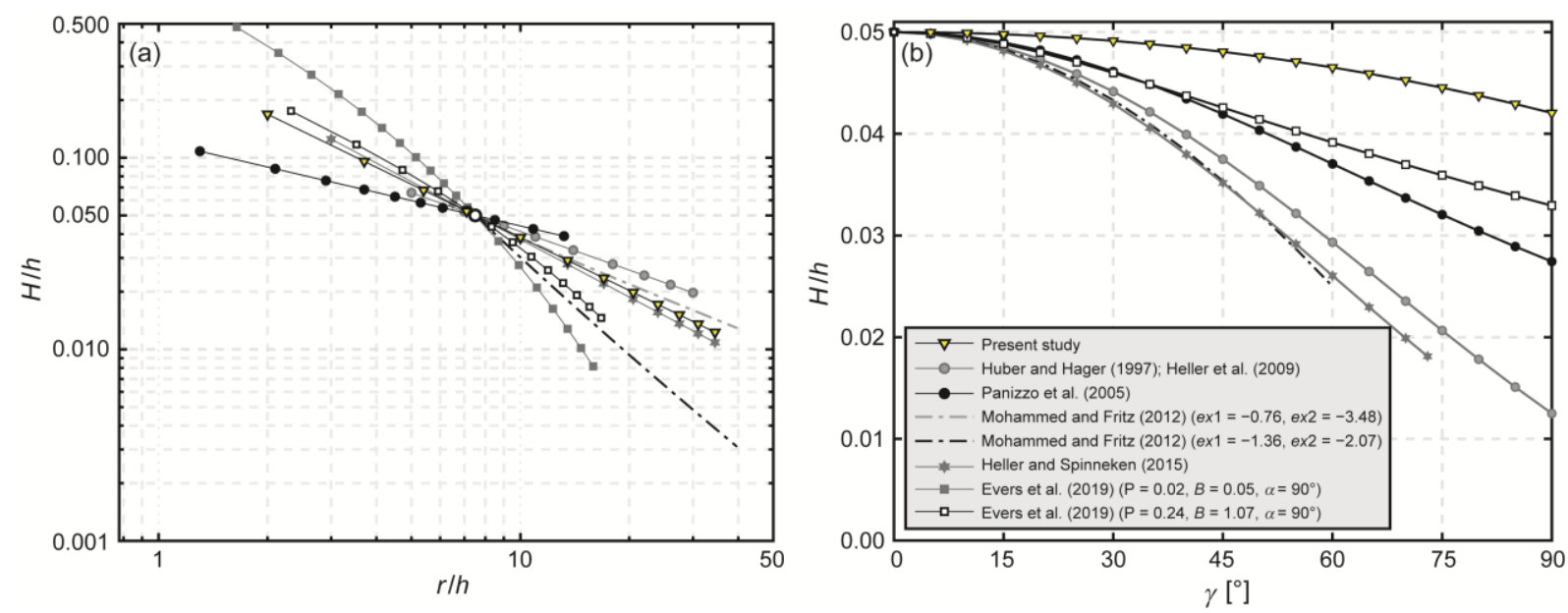

Fig. 12. Comparison of the relative iceberg- with landslide-tsunami height $H / h$ decay with the reference point (O) at $\left(r / h=7.5, \gamma=0^{\circ}\right)$ : (a) $H / h$ versus relative distance $r / h$ and (b) $H / h$ versus wave propagation angle $\gamma$. The data of each of the two scenarios of Mohammed and Fritz (2012) and of Ever et al. (2019a) overlap in (b).

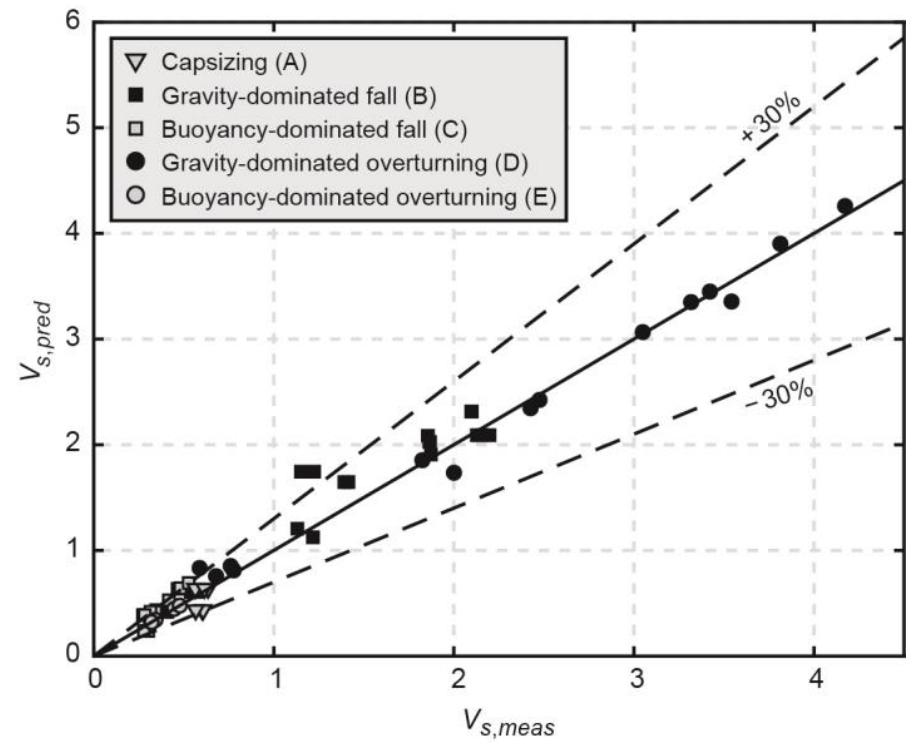

Fig. A.1. Predicted $V_{s, p r e d}$ versus measured $V_{s, \text { meas }}$ iceberg (impact) velocities $\left(R^{2}=0.98\right)$. 

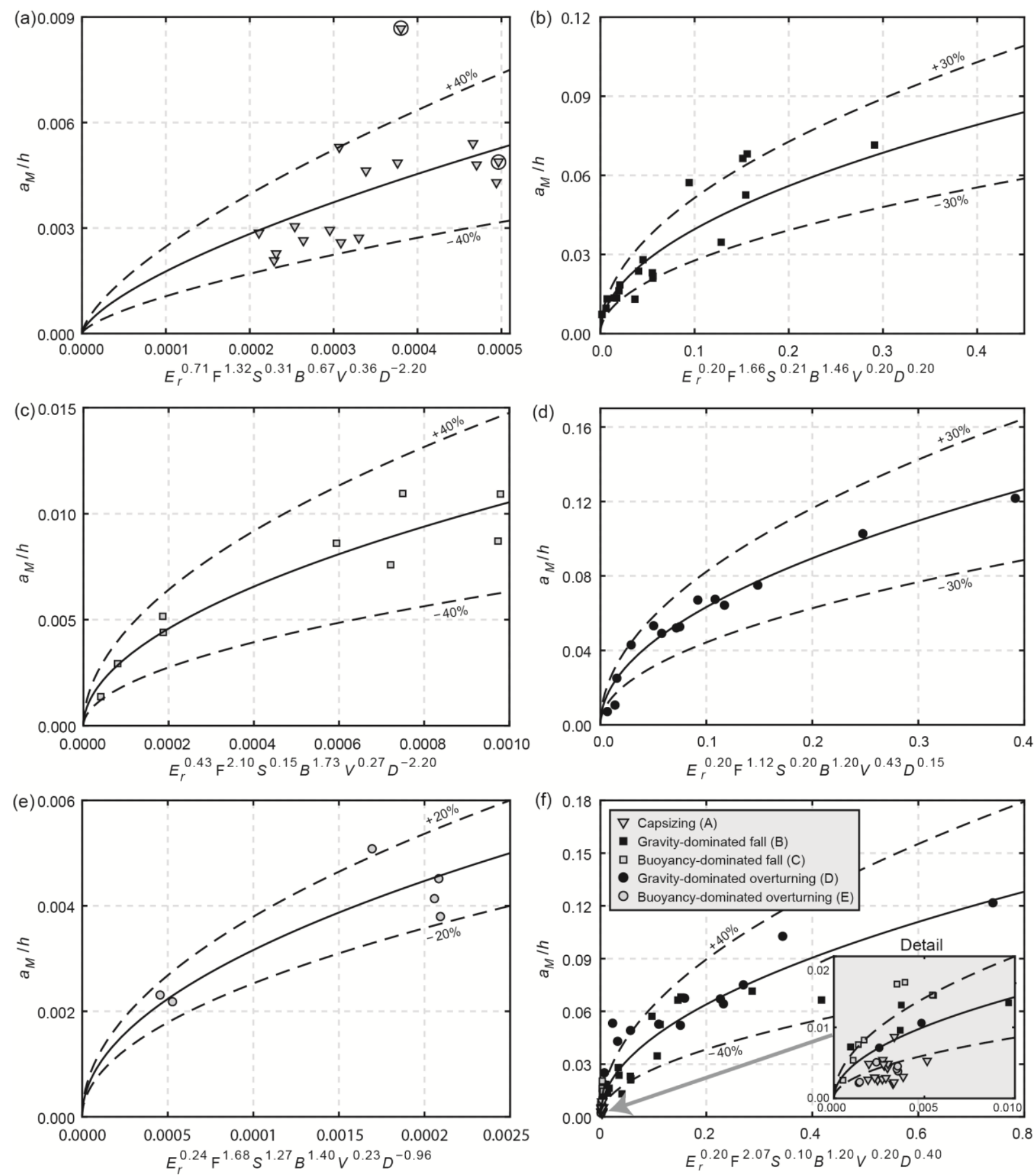

Fig. B.1. Maximum relative wave amplitude $a_{M} / h$ versus a dimensionless parameter combination: (a) mechanism A with (-) Eq. (B.1) (--) $\pm 40 \%$ deviation $\left(R^{2}=0.34\right)$ and the data points of the two harder pushed experiments encircled, (b) mechanism B with (-) Eq. (B.2) (--) $\pm 30 \%$ deviation $\left(R^{2}=0.82\right)$, (c) mechanism C with $(-)$ Eq. (B.3) (--) $\pm 40 \%$ deviation $\left(R^{2}=0.90\right)$, (d) mechanism D with $(-)$ Eq. (B.4) (--) $\pm 30 \%$ deviation $\left(R^{2}=0.96\right)$, (e) mechanism E with (-) Eq. (B.5) $(--) \pm 20 \%$ deviation $\left(R^{2}=\right.$ 
$0.75)$ and (f) all mechanisms with (-) Eq. (B.6) (--) $\pm 40 \%$ deviation $\left(R^{2}=0.91\right)$. For the notation see (f).
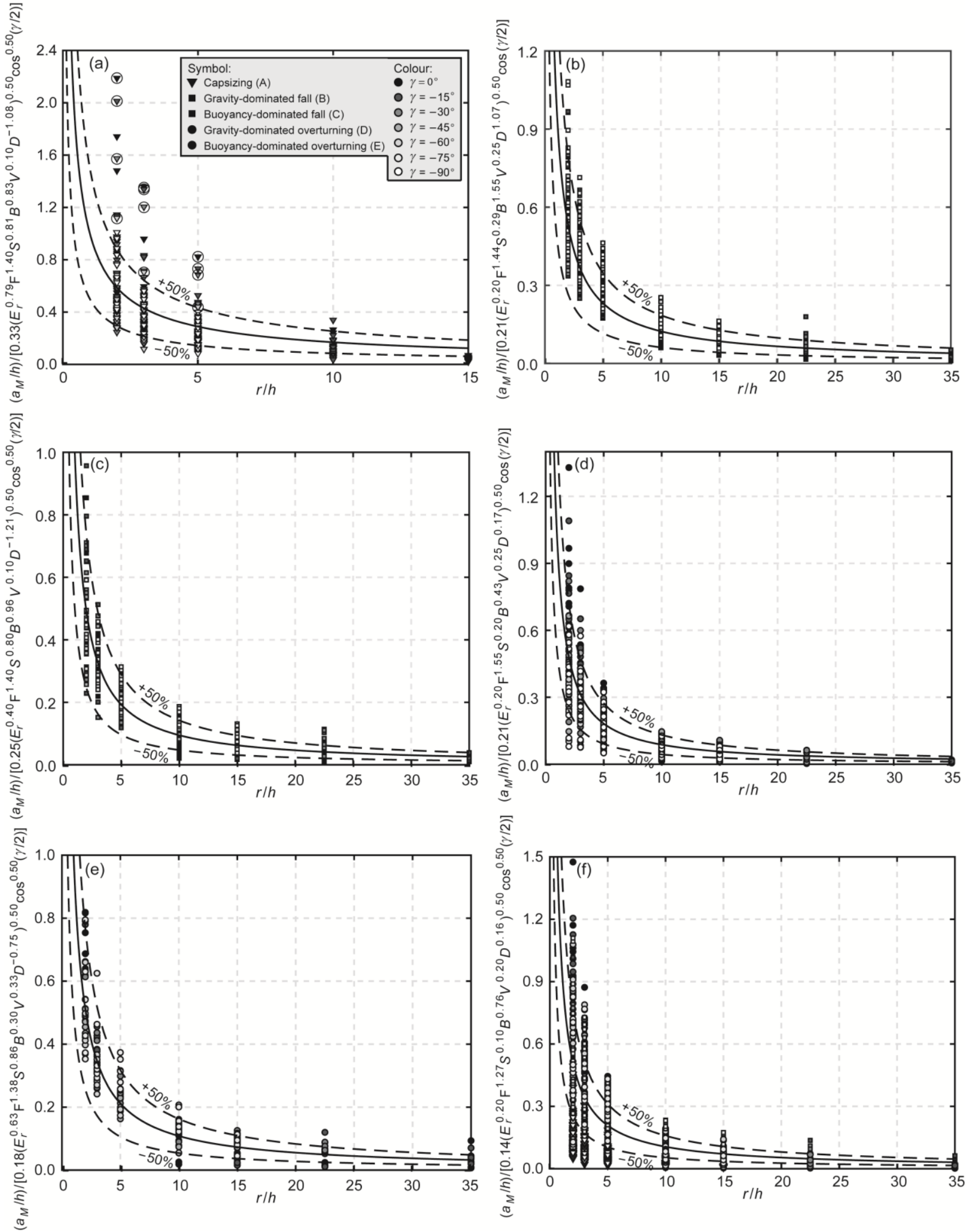
Fig. B.2. Normalised relative maximum wave amplitude $a_{M} / h$ decay for all experiments with the relative radial distance $r / h$ : (a) mechanism A with (-) Eq. (B.7) (--) $\pm 50 \%$ deviation $\left(R^{2}=0.39\right)$ and the 11 largest outliers from the two harder pushed experiments encircled, (b) mechanism B with (-) Eq. (B.8) (--) $\pm 50 \%$ deviation $\left(R^{2}\right.$ $=0.89),(\mathrm{c})$ mechanism $\mathrm{C}$ with $(-)$ Eq. (B.9) $(--) \pm 50 \%$ deviation $\left(R^{2}=0.86\right),(\mathrm{d})$ mechanism D with (-) Eq. (B.10) (--) $\pm 50 \%$ deviation $\left(R^{2}=0.84\right),(\mathrm{e})$ mechanism $\mathrm{E}$ with (-) Eq. (B.11) (--) $\pm 50 \%$ deviation $\left(R^{2}=0.88\right)$ and (f) all mechanisms with $(-)$ Eq. (B.12) (--) $\pm 50 \%$ deviation $\left(R^{2}=0.78\right)$. For the notation see (a).
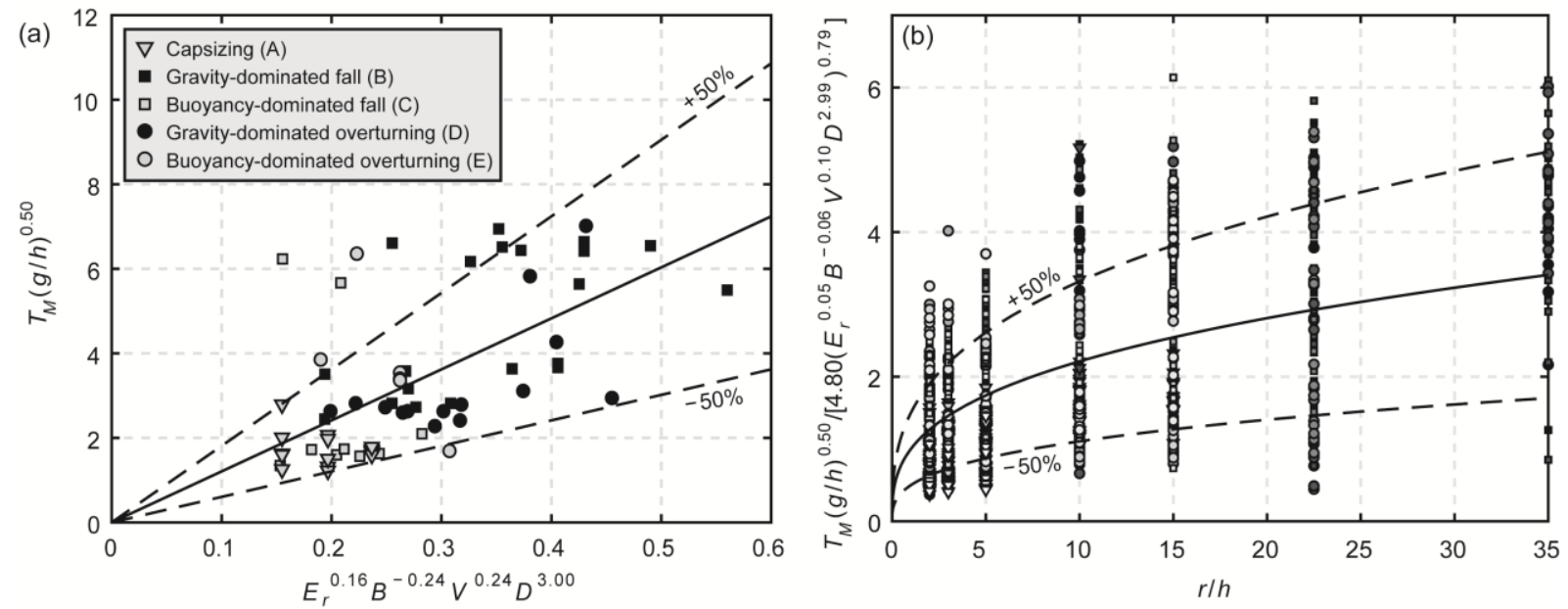

Fig. B.3. Relative wave period $T_{M}(g / h)^{0.50}$ of the maximum wave height for all experiments in (a) versus a dimensionless parameter combination with (-) Eq. (B.13) (--) $\pm 50 \%$ deviation $\left(R^{2}=0.39\right)$ and in (b) normalised $T_{M}(g / h)^{0.50}$ versus the relative distance $r / h$ with (-) Eq. (B.14) (--) $\pm 50 \%$ deviation $\left(R^{2}=0.35\right)$. For the notation for (b) see Fig. 10(a). 



Fig. B.4. Relative wave height $H_{1} / h$ and amplitude $a_{1} / h$ of the first wave for all experiments: (a) $H_{1} / h$ versus a dimensionless parameter group with (-) Eq. (B.15) (--) $\pm 40 \%$ deviation $\left(R^{2}=0.89\right)$, (b) $a_{1} / h$ versus a dimensionless parameter group with (-) Eq. (B.16) (--) $\pm 40 \%$ deviation $\left(R^{2}=0.82\right)$, (c) normalised $H_{1} / h$ versus the relative distance $r / h$ with (-) Eq. (B.17) (--) $\pm 50 \%$ deviation $\left(R^{2}=0.80\right)$ and (d) $a_{1} / h$ versus $r / h$ with (-) Eq. (B.18) (--) $\pm 50 \%$ deviation $\left(R^{2}=0.68\right)$. For the notations see (a) and (c). 

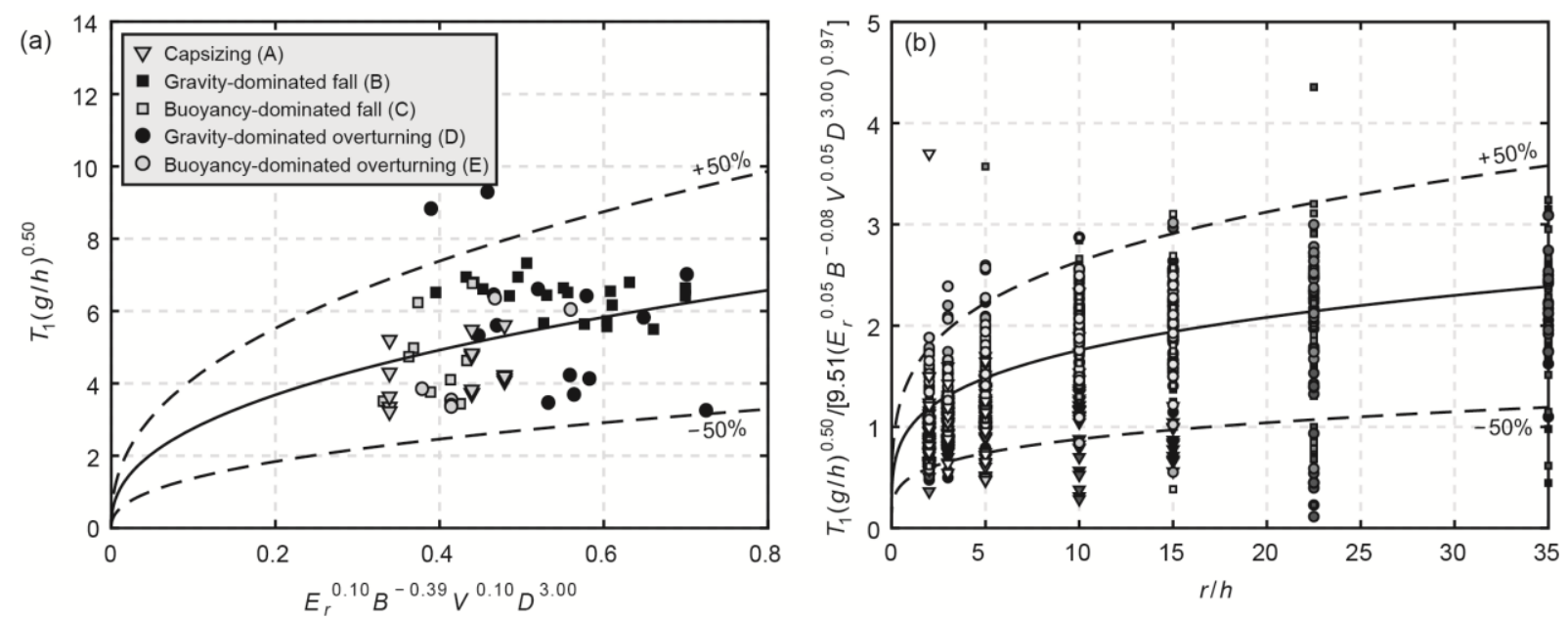

Fig. B.5. Relative first wave period $T_{1}(g / h)^{0.50}$ for all experiments: (a) $T_{1}(g / h)^{0.50}$ versus a dimensionless parameter group with (-) Eq. (B.19) (--) $\pm 50 \%$ deviation $\left(R^{2}=0.11\right)$ and (b) normalised $T_{1}(g / h)^{0.50}$ versus the relative distance $r / h$ with (-) Eq. (B.20) (--) $\pm 50 \%$ deviation $\left(R^{2}=0.57\right)$. For notation for (b) see Fig. 10(a). 